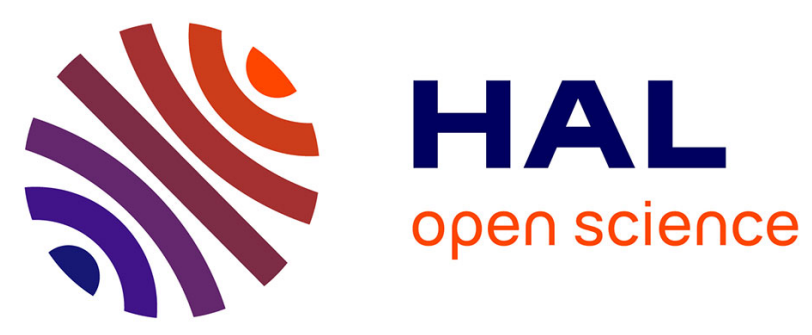

\title{
A weak shear web model for deflection analysis of deep composite box-type beams
}

\author{
S. R. Atashipour, U. A. Girhammar, Noël Challamel
}

\section{To cite this version:}

S. R. Atashipour, U. A. Girhammar, Noël Challamel. A weak shear web model for deflection analysis of deep composite box-type beams. Engineering Structures, 2018, 155, pp.36-49. 10.1016/j.engstruct.2017.10.073 . hal-01693901

\section{HAL Id: hal-01693901 https://hal.science/hal-01693901}

Submitted on 31 Dec 2019

HAL is a multi-disciplinary open access archive for the deposit and dissemination of scientific research documents, whether they are published or not. The documents may come from teaching and research institutions in France or abroad, or from public or private research centers.
L'archive ouverte pluridisciplinaire HAL, est destinée au dépôt et à la diffusion de documents scientifiques de niveau recherche, publiés ou non, émanant des établissements d'enseignement et de recherche français ou étrangers, des laboratoires publics ou privés. 


\title{
A weak shear web model for deflection analysis of deep composite box-type beams
}

\author{
S.R. Atashipour ${ }^{\mathrm{a}, \mathrm{b}, *}$, U.A. Girhammar ${ }^{\mathrm{a}}$, N. Challamel ${ }^{\mathrm{c}}$ \\ a Department of Engineering Sciences and Mathematics, Division of Wood Science and Engineering, Luleå University of Technology, Skellefteå, Sweden \\ ${ }^{\mathrm{b}}$ Department of Architecture and Civil Engineering, Division of Structural Engineering, Chalmers University of Technology, SE-412 96 Gothenburg, Sweden \\ ' Université de Bretagne Sud, UBS - Institut Dupuy de Lôme, Centre de Recherche, Rue de Saint Maudé, BP92116, 56321 Lorient Cedex, France
}

Deep box-type beams, consisting of framing members and sheathings, are sensitive to shear deformations and hence appropriate refined theories or complicated magnification factors are needed to be used to obtain accurate results. For sheathings or webs between the framing members that are weak in shear, additional shear deformations occur corresponding to the relative axial displacement between the framing members. These sandwich-type or partial interaction-type of in-plane shear behaviour between the framing members, needs to be taken into account, especially when the web shear stiffness is very low. The composite box-type beam treated here is composed of three framing members with sheathings on both sides. To incorporate effects of the sheathings shear deformations between the framing members on the deflection, the sheathings, here called web interlayers, are modelled as shear media with equivalent slip moduli corresponding to a partially interacting composite beam model. Governing equilibrium equations of the model are obtained using the minimum total potential energy principle and solved explicitly. The obtained results are compared with those based on different conventional beam theories and 3-D finite element (FE) simulations. It is shown that the model is capable of predicting accurately the deflection for a wide range of geometry and property parameters. It is demonstrated that the deflection of such deep box-type beams can be expressed as the summation of three different effects, namely bending deformations, conventional shear deformations in the framing members and sheathings, and additional in-plane shear deformations or shear slips of the weak web causing relative axial displacements between the framing members.

\section{Introduction}

Timber structures are of increasing interest for the construction of multi-storey buildings. A Scandinavian glulam manufacturer, Moelven Töreboda $\mathrm{AB}$, has developed a prefabricated beam-and-post system named "Trä8" for the market of non-residential multi-storey timber buildings. The system is based on the rectangular modules, with maximum spans of $8 \mathrm{~m}$ (hence the name Trä $8=$ timber 8 ), for details, see [1-3]. The Trä8 system is composed of several elements and components which are mostly produced off-site. They are assembled after delivery to the building site. The main elements of the system are continuous columns, beams, prefabricated stabilising wall elements, prefabricated floor cassettes and roof elements (Fig. 1) [1-3].

The stabilising wall element of the Trä8-system is a continuous, prefabricated, proprietary vertical element with a composite box-type of timber cross-section which is installed together with ordinary glulam columns and beams (post-and-beam system), and prefabricated floor and roof elements. The stabilising walls are preferably placed along the facade of the building (see Fig. 1).

The beams of Trä8 are connected to the continuous columns in a theoretically pinned manner and these ordinary columns are also pinned connected to the foundation. However, the stabilising wall element is theoretically clamped to the substrate. This clamping of the stabilising element to the foundation can be designed as shown in Fig. 2 $[2,3]$.

The composite stabilising wall element is considered as a vertical cantilever beam clamped to the substrate and subjected to a horizontal point load from the wind (Fig. 3a). This stabilising element is a deep box-type beam comprised of glued-laminated timber for the three framing members and laminated veneer lumber (LVL) for the sheathing on both sides (Fig. 3b). The sheathing is glued and screwed to the framing members using phenol-resorcinol adhesive to make perfect bounding between them. The screws both connect the sheathing to the skeleton and apply the pressure during bonding. The screws also

\footnotetext{
* Corresponding author at: Department of Architecture and Civil Engineering, Division of Structural Engineering, Chalmers University of Technology, SE-412 96 Gothenburg, Sweden. E-mail address: rasoul.atashipour@chalmers.se (S.R. Atashipour).
} 


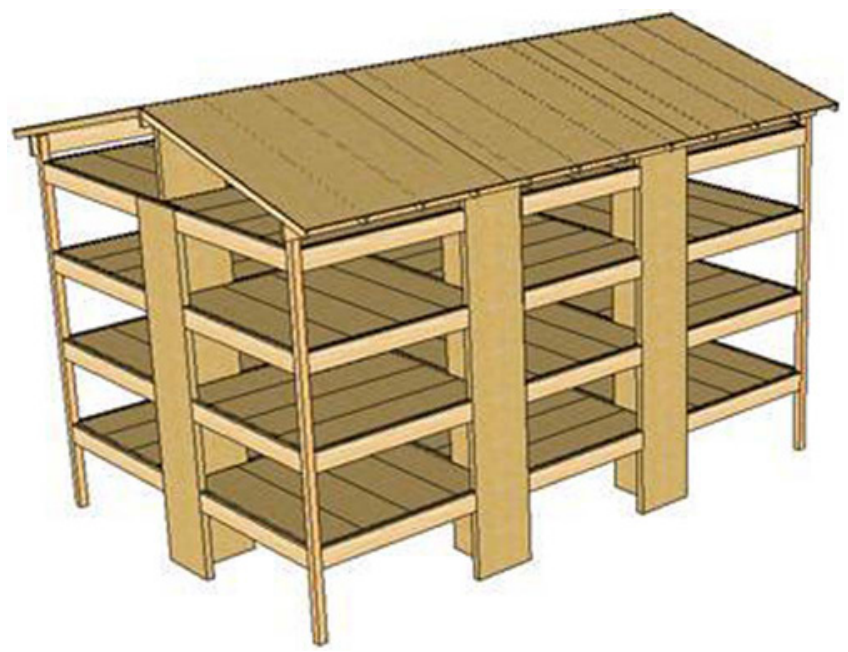

Fig. 1. Trä8 main components, including stabilising wall elements, in a multi-storey timber building [1-3].

provide additional safety in case of failure of the glue. Accurate prediction of the transverse deflection including shear effects in the plane of this structural element is of importance to ensure limited deformations in the serviceability limit state and for its optimal design.

The deflection is due to bending and shear. Accurate prediction of the shear deformations of the stabilising wall element, as a deep composite box-type beam, was investigated by Girhammar and Atashipour in a previous study [1]. In that study, a formula for the shear correction factor was derived for this kind of box-type cross-section with abrupt geometrical and property variations. The web was modelled in the same way as the framing members. This model works well for ordinary practical ranges of geometrical and property parameters, but not for situations when the web is very weak in shear. As pointed out by Girhammar and Atashipour [1], a relative displacement along the $x$-axis between the framing members due to the weak shear webs could be observed on the contour plot from a 3-D finite element analysis. A corresponding plot is re-illustrated from [1] and shown in Fig. 4, for the Trä8 stabilising wall element as a cantilever deep beam subjected to a point load from wind. The point load is uniformly distributed over the whole cross-section at one end and, at the other end, the beam is clamped by setting the 3-D displacement components to zero. The deflection in the transverse direction (i.e. along $\mathrm{z}$-axis according to Fig. 3a) at the upper and lower surfaces and at the centre of the crosssection is shown in the figure. It is observed that there is a relative horizontal displacement between the upper and lower flanges due to the weak shear web which results in an increase in the deflection.

This behaviour is similar to the behaviour of a sandwich-type of beam. There is equivalence with respect to the fundamental behaviour and governing differential equations between shear connections (lap
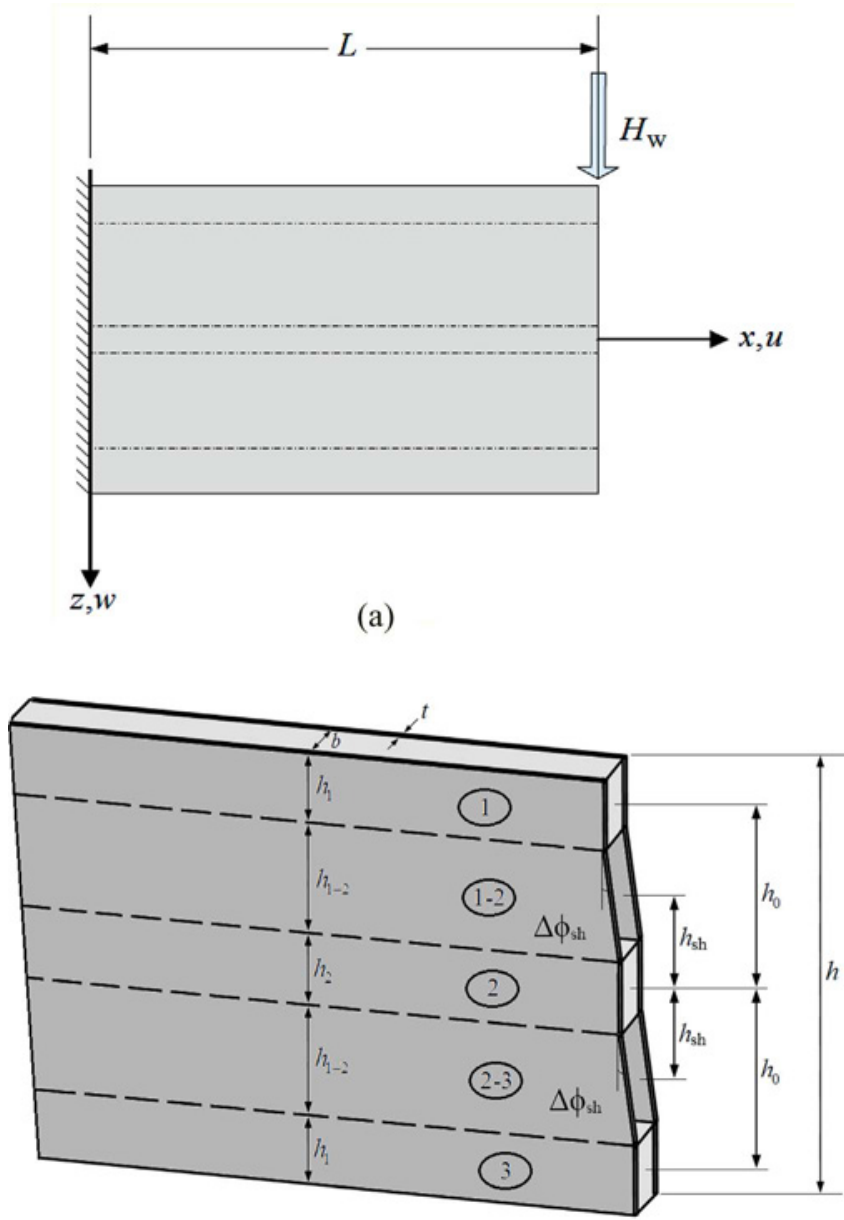

(b)

Fig. 3. (a) Trä8 stabilising wall element, where the coordinate system is defined (for convenience, the element is rotated); (b) Perspective of the cross-section in a deformed state due to "shear slip" between the framing members. The digits 1 and 2 refer to the upper/lower and intermediate framing members, respectively including the sheathing on each side. $h_{0}=\left(h-h_{1}\right) / 2, h_{\mathrm{sh}}=\left(h_{1-2}+h_{2}\right) / 2$.

joints mechanically or adhesively jointed), see e.g. the fundamental works [4-9], sandwich constructions (sandwich beams and columns with cores of low shear rigidity), see e.g. the fundamental works [10-12], and composite structures with interlayer slip, see e.g. the works [13-16]. The equivalent slip modulus for the sheathing depends on its shear modulus, thickness and height.

In the present study, the shear effect of the web between the framing members is modelled as an interlayer with a shear stiffness corresponding to a slip modulus in a partially interacting composite beam and the relative displacement between the framing members
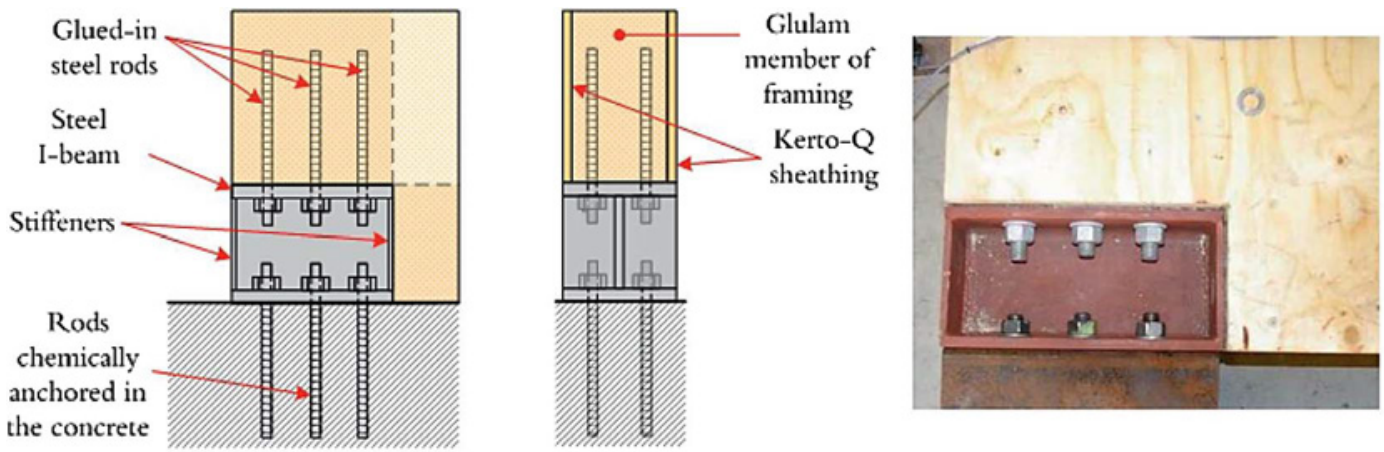

Fig. 2. Anchorage device with glued-in rods for fixing the stabilising element to the foundation $[2,3]$. 


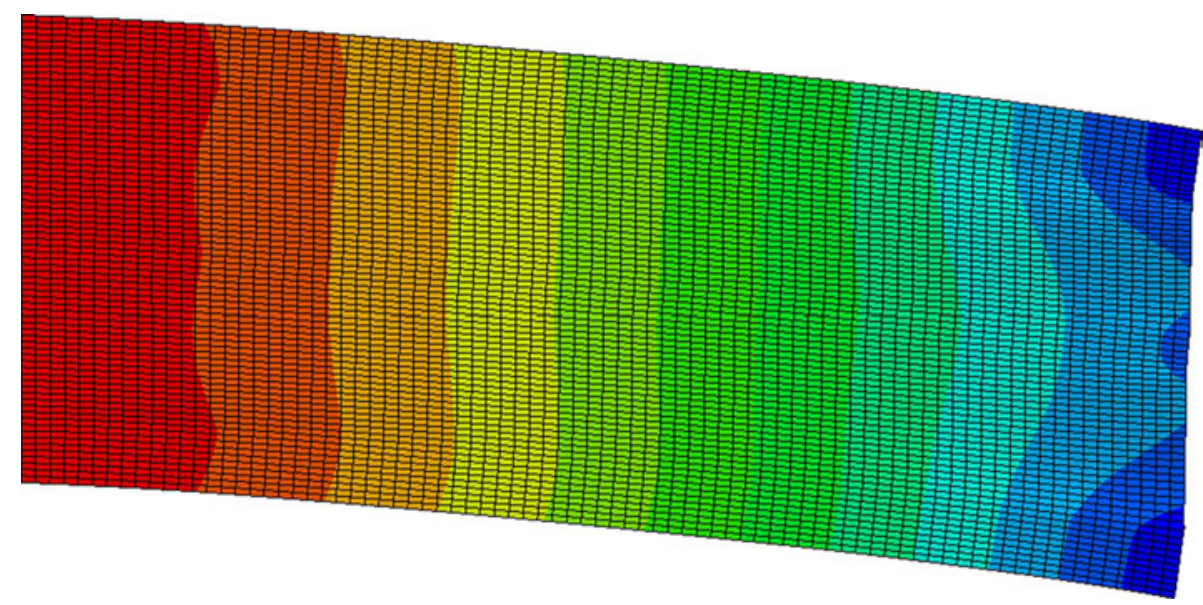

Fig. 4. Relative displacement between the framing members in a 3-D ABAQUS simulation of bending of a clamped stabilising wall element due to weak shear web (the figure is reproduced from [1]). For details of the material properties and geometries, cf. Fig. A.1 in Appendix A.

corresponds to slip. This model for the shear deflections is valid also for very low shear stiffness values of the web. Moreover, this model is also capable of including the possible relative displacement between the framing members due to "axial" shear displacements in addition to the transverse shear displacement, cf. [12], where a simply supported sandwich beam with a couple applied at one end is discussed. However, this type of deformation of the core or web is always zero if the beam is loaded in a symmetrical manner, or when the relative "axial" displacement of the faces or framing members is prevented [12], for example at a clamped end.

The minimum total potential energy principle in conjunction with an equivalent partial composite interaction theory with Timoshenko assumptions is used to obtain the governing equilibrium equations and the pertaining boundary conditions for the static deflection of a cantilevered box-type beam subjected to a point load at its tip. The model then corresponds to three separated framing layers and two web interlayers with shear slips. Next, a powerful mathematical procedure is employed to recast the coupled set of governing equations into an uncoupled form. The new uncoupled equations are solved explicitly without any approximation and the boundary conditions are exactly satisfied. The obtained closed-form formula can accurately predict the deflections. In order to illustrate the different contributions, the proportion from the bending deformation, the conventional shear deformation in the framing and sheathing, and the web "shear slip" to the total deflection are shown separately.

\section{Analysis of the problem}

A stabilising wall element composed of three framing members and sheathings on each side is considered. The sheathings are glued to both sides of the framing members to make a perfectly bonded deep box-type beam. This structural element is clamped to the substrate and is at its end subjected to a transverse point load from wind in the $x-z$ plane (Fig. 3a). The sheathings between the framing members, the shear web interlayers, are much weaker in shear than the framing members and will here be treated as weak shear webs between the framing members in something of a corresponding way as the weak shear core in a sandwich-type of beam (Fig. 3b). Results of an accurate 3-D finite element simulation of the problem confirm this type of shear behaviour or, in other words, the relative displacement between the framing members due to this weakness of the sheathings in shear corresponds to "slip" in a partially interacting composite beam (cf. Figs. 3 b and 4). This relative displacement considerably affects the deflection of the stabilising wall element and therefore is of great importance to be studied for a reliable design based on serviceability limit states.

\subsection{Previous engineering method for shear deformation analysis [1]}

Girhammar and Atashipour [1] studied shear deflections of the same kind of stabilising wall panel using different types of shear deformation models. Linear elastic conditions were assumed as well as full interaction between the framing and sheathing components in the composite section. They employed an energy-based engineering method to present an explicit formula for predicting the shear correction factor $\left(K_{\mathrm{s}}\right)$ for deep composite beams having a symmetric box-type of cross-section (or similar cross-sections with abrupt variations of geometry and properties). The model was based on using an equivalent shear angle for the whole cross-section which obviously is not the real behaviour according to Fig. 4.

The expression for the maximum shear deflection for the cantilever in Fig. 3a was given in [1] as

$w_{\text {max,shear }}=\frac{1}{K_{\mathrm{s}}} \frac{H_{\mathrm{w}} L}{G A_{0}}$

The shear deflection equation was first presented by Bresse [17] for isotropic cantilever beam without the concept of the shear correction factor (i.e. $K_{\mathrm{s}}=1$ ), and later by Timoshenko [18] with the correction factor $K_{\mathrm{s}}=2 / 3$. In Eq. (1), $H_{\mathrm{w}}$ is the applied point load, $L$ the length of the cantilever, and the total shear stiffness of the different cross-sectional parts, $G A_{0}$, is given by

$G A_{0}=\sum G_{i} A_{i}$

where $G_{i}$ and $A_{i}$ are the shear modulus and the corresponding area of the ith material, respectively. This stiffness value can also be written as, $G A_{0}=G_{\text {eq,tot }} A_{\text {tot }}$, where $A_{\text {tot }}$ is the total area of the cross-section and $G_{\text {eq,tot }}$ is the equivalent shear stiffness for the whole cross-section. The expression for the derived shear correction factor $\left(K_{\mathrm{s}}\right)$ was given as

$K_{\mathrm{s}}=\frac{E I_{\infty}^{2}}{G A_{0}}\left[\int_{A} \frac{[E S(z)]^{2}}{G_{\mathrm{eq}}(z)[d(z)]^{2}} \mathrm{~d} A\right]^{-1}=\frac{E I_{\infty}^{2}}{G A_{0}}\left[\int_{-h / 2}^{h / 2} \frac{[E S(z)]^{2}}{G_{\mathrm{eq}}(z) \cdot d(z)} \mathrm{d} z\right]^{-1}$

where $E I_{\infty}$ is the total bending stiffness (including the sheathings) of the whole cross-section (corresponding to a fully composite cross-section with no interlayer slips), and $E S(z)$ is the first moment of the axial stiffness of the sheared area at the $z$-level, i.e.

$$
\begin{aligned}
E S(z) & =\int_{A_{\mathrm{S}}} E_{x}(y, z) z \cdot \mathrm{d} A=\int_{-d / 2}^{d / 2}\left[\int_{z}^{h / 2} E_{x}(y, z)|z| \cdot \mathrm{d} z\right] \cdot \mathrm{d} y \\
& =\int_{-b / 2-t}^{b / 2+t}\left[\int_{z}^{h / 2} E_{x}(y, z)|z| \cdot \mathrm{d} z\right] \cdot \mathrm{d} y
\end{aligned}
$$

and $d(z)$ is the total equivalent width of the cross-section at the $z$-level, and the equivalent shear modulus at the $z$-level, $G_{\mathrm{eq}}(z)$, is expressed as 
$G_{\mathrm{eq}}(z)=\frac{\int_{A_{z}} G(y, z) \mathrm{d} A_{z}}{\int_{A_{z}} \mathrm{~d} A_{z}}=\frac{\left[\int_{-d / 2}^{d / 2} G(y) \mathrm{d} y\right](z)}{\left[\int_{-d / 2}^{d / 2} \mathrm{~d} y\right](z)}=\frac{\left[\sum_{n} G_{n} d_{n}\right](z)}{\left[\sum_{n} d_{n}\right](z)}$

where $G_{n}, d_{n}$ are the shear modulus and the corresponding width, respectively, of the $n$th material at $z$-level. This modulus is obtained by introducing a shear angle at the $z$-level assumed constant over the whole width of the cross-section as $\gamma(x, z)=\tau(x, z) / G_{\mathrm{eq}}(z)$ for $-d / 2 \leqslant y \leqslant d / 2$, where $\tau(x, z)$ is the equivalent shear stress assumed uniformly distributed over the width $d(z)$ at the $z$-level (independent of $y)$. The shear modulus for a constant composite cross-section varies in general with respect to both $y$ - and z-axis, i.e. $G(y, z)$, but to be consistent with the assumption above an equivalent shear modulus valid for the whole width of the cross-section at each $z$-level is needed, i.e. $G(y, z)=[G(y)](z)=G_{\mathrm{eq}}(z)$. Thus, this modulus is a kind of average shear modulus along the width of the cross-section, varying in general in the $z$-direction (a remark that this parameter has to be evaluated at the $z$-level should have been given more explicitly in paper [1]). The equivalent shear modulus is evaluated as the shear stiffness over the corresponding area at a certain $z$-level, i.e. for an area strip in the $y$ direction of unit depth in the $z$-direction $\left(\mathrm{d} A_{z}=\mathrm{d} y \cdot 1\right)$.

This evaluation procedure for the cross-section of the Trä8 wall element is illustrated in Appendix A, where various notations and parameter values are shown. In Girhammar and Atashipour [1], an explicit formula for the shear correction factor for the Trä8 cross-section is also given.

Examining the parameter, $G_{\text {eq }}(z)$, it becomes obvious that it equals $G_{\text {sh }}$ at the level of the sheathing (sh) or web (w) between the framing members according to Eq. (A.8) in Appendix A. If this value tends to zero for very thin shear webs or for very low shear rigidities, the shear correction factor also tends to zero and, therefore, the shear deflections tends to infinity. Mechanically, this means that the interaction between the framing members is decreasing and they will increase in sliding relative one another. Evidently, the finite real deflection value of the structure is corresponding to a case with non-composite interaction between the sub-elements. Therefore, another type of model is needed for small shear stiffness values of the webs.

\subsection{Establishing a new model: basics and assumptions}

To obtain the governing equilibrium equations and boundary conditions for an element corresponding to the cantilevered stabilising wall element subjected to a point load, the total potential energy of the system is formulated taking the bending and shear deformations (according to the Timoshenko model) into account together with the additional shear weak behaviour of the webs. A basic uniform shear model is assumed, i.e. each framing member and sheathing is supposed to deform equally in shear (cf. [15]). The additional shear deformation of each web is modelled as an interlayer having a corresponding slip modulus. However, the axial and bending stiffness of each web is also taking into account. The normal force in the web affects not only the axial stiffness, but also the bending stiffness according to Steiner's theorem. The total potential energy can then be written as

$$
\begin{aligned}
& U\left[u_{1}, u_{2}, u_{3}, u_{\mathrm{sh}, 1-2}, u_{\mathrm{sh}, 2-3}, \varphi, w\right]= \\
& \frac{1}{2} \int_{0}^{L}\left\{E A_{1} u_{1}^{\prime 2}+E A_{2} u_{2}^{\prime 2}+E A_{1} u_{3}^{\prime 2}+E A_{\mathrm{sh}, 1-2} u_{\mathrm{sh}, 1-2}^{\prime 2}+E A_{\mathrm{sh}, 1-2} u_{\mathrm{sh}, 2-3}^{\prime 2}\right. \\
& \quad+2 E I_{1} \varphi^{\prime 2}+E I_{2} \varphi^{\prime 2}+2 E I_{\mathrm{sh}, 1-2} \varphi^{\prime 2} \\
& \quad+2 K_{\mathrm{s}} G A_{1}\left(\varphi+w^{\prime}\right)^{2}+K_{\mathrm{s}} G A_{2}\left(\varphi+w^{\prime}\right)^{2}+2 K_{\mathrm{s}} G A_{\mathrm{sh}, 1-2}\left(\varphi+w^{\prime}\right)^{2} \\
& \left.\quad+k\left(u_{2}-u_{1}-h_{0} \varphi\right)^{2}+k\left(u_{3}-u_{2}-h_{0} \varphi\right)^{2}\right\} d x-H_{\mathrm{w}} w(L)
\end{aligned}
$$

where $u_{i}$ and $u_{\mathrm{sh}, \mathrm{i}-\mathrm{j}}$ are respectively the axial displacement of the $i$ th framing member and the $i$-jth sheathing interlayer, $w$ is the transverse deflection, $\varphi$ the rotation function for the in-plane deformations in the framing members, $H_{\mathrm{w}}$ the point load from wind, $L$ the length of the element, $k$ the slip modulus of the interlayer webs, $t$ and $b$ the thickness of the sheathing and width of the glulam framing member, and $h_{0}$ and $h_{s h}$ are the distance between the centroid of the intermediate framing member to the centroid of the upper/lower framing member and the centroid of the interlayer web (empty box), respectively (see Fig. 3). Also, $h_{1}$ and $h_{2}$ are respectively the depth of upper/lower and intermediate framing member, $h_{1-2}$ is the depth of the interlayer web and $h_{0}$ is the total depth of the stabilising wall element. The additional shear deformation of the interlayer web, or so-called shear slip, is indicated by the angle $\Delta \phi_{\mathrm{sh}}$ on Fig. 3b. $K_{\mathrm{s}}$ the shear correction factor (with this model there is no need for the complicated shear correction factor derived in [1] since all sub-elements are considered separately and are of rectangular type). The stiffness parameters for the framing layers (framing member including pertaining sheathing on both sides) and the web interlayer (the two sheets) are given by

$E A_{i}=\left(E_{\mathrm{f}} b+2 E_{\mathrm{sh}} t\right) h_{i}$,

$G A_{i}=\left(G_{\mathrm{f}} b+2 G_{\mathrm{sh}} t\right) h_{i}$,

$E I_{i}=\frac{1}{12}\left(E_{\mathrm{f}} b+2 E_{\mathrm{sh}} t\right) h_{i}^{3}, \quad(i=1,2)$.

$E A_{\text {sh,1-2 }}=2\left(E_{\mathrm{sh}} t h_{1-2}\right)$,

$G A_{\text {sh,1-2 }}=2\left(G_{\text {sh }} t h_{1-2}\right)$,

$E I_{\mathrm{sh}, 1-2}=2\left(\frac{1}{12} E_{\mathrm{sh}} t h_{1-2}^{3}\right)$.

where $E_{\mathrm{f}}$ and $E_{\mathrm{sh}}$ are Young's modulus of glulam framing and LVL sheathing layers, respectively. Also, $G_{\mathrm{f}}$ and $G_{\mathrm{sh}}$ are respectively the shear modulus of the glulam framing and LVL sheathing layers.

Here, we define the axial displacements of the sheathing interlayers or webs, $u_{\mathrm{sh}, \mathrm{i}-\mathrm{j}}$, in terms of those of the upper/lower framing members to reduce the number of the unknown functions and simplify the model and analysis. To this end, we set (see Fig. 5):

$u_{\text {sh, } 1-2}=\eta u_{1}$

$u_{\mathrm{sh}, 2-3}=\eta u_{3}$

where $\eta$ is a proportional factor. Eq. (8) is based on the fact that the axial displacement of any sheathing interlayer is proportional to that of the neighbour framing member. Obviously, this assumption is valid for linear elastic range of deformations.

To determine the proportional factor $\eta$ based on the assumption of Eq. (8), the state of axial deformation of different framing layers and the interlayer sheathings of the previously described beam structure with a symmetric cross-section is shown in Fig. 5. In this figure, a straight dash line in red shows the location of axial deformation vectors in absence of the additional shear slip due to the weak shear web. In fact, the additional shear deformations in the web interlayers cause a relaxation in the axial deformations and reduce them. The corresponding location of the axial deformation vectors is determined in Fig. 5 by some continuous segment lines in blue having different slopes. To be able to present an approximate simple engineering formula for the coefficient, $\eta$, a straight dash line in black is depicted approximately passing through the end points of the axial deformation vectors. From the geometry of the vectors in Fig. 5, one can be obtained

$\frac{u_{\mathrm{sh}, 1-2}}{u_{1}}=\frac{u_{\mathrm{sh}, 2-3}}{u_{3}} \cong \frac{h_{\mathrm{sh}}}{h_{0}}$

where $h_{\mathrm{sh}}=\left(h_{1-2}+h_{2}\right) / 2$ is the distance between the centroid of the corresponding interlayer web to the centroid of the intermediate framing member (see Fig. 3b). From comparing Eqs. (8) and (9) it follows that

$\eta \cong \frac{h_{\text {sh }}}{h_{0}}$

Here, we emphasise that the obtained equation for the proportional coefficient $\eta$ is not exact. But they represent sufficiently accurate engineering formulas. It will be shown in Section 2.4 that Eq. (10) results in a correct definition of the bending stiffness corresponding to a full- 


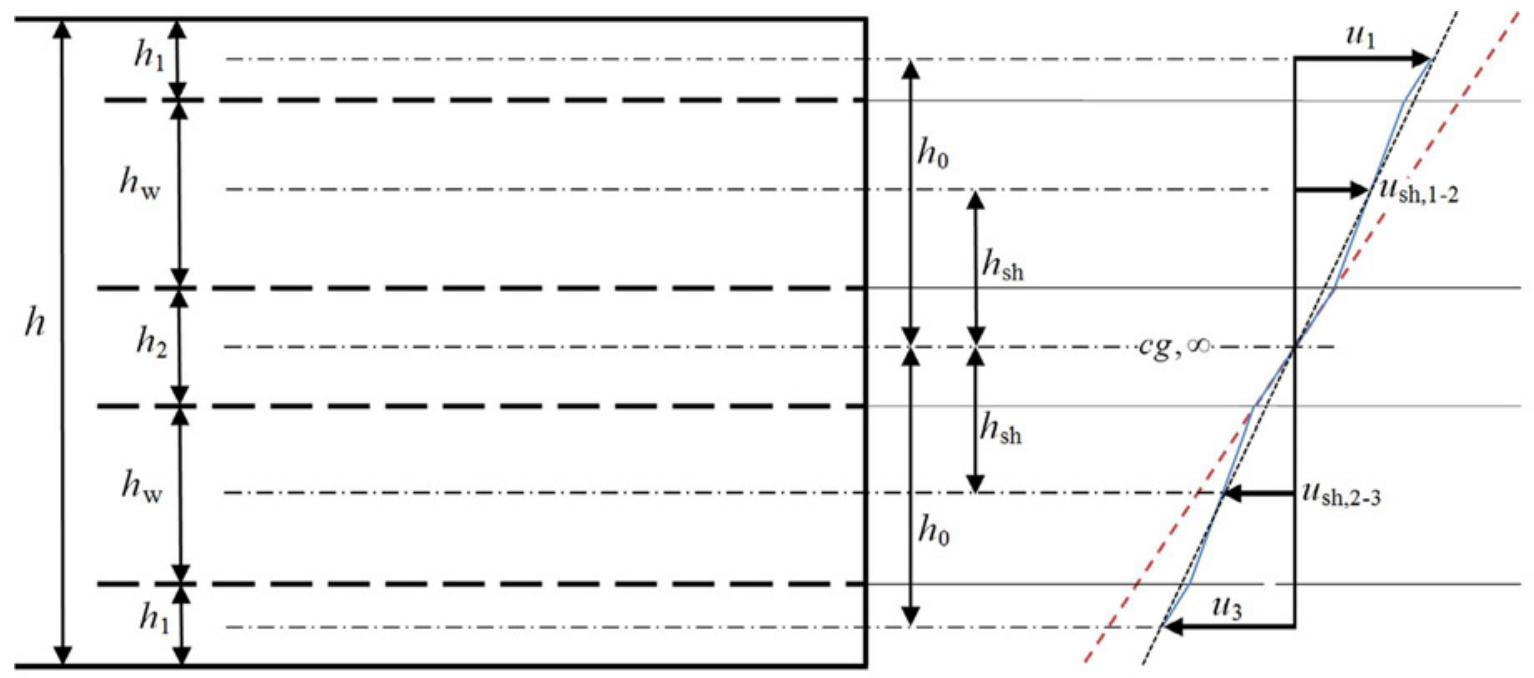

- The true location of axial deformations.

- - The location of axial deformations in absence of the additional shear slip due to the weak shear webs.

..-.- An imaginary straight line approximately passing through the end points of the axial deformation vectors.

Fig. 5. Illustration of the axial deformations of the stabilising wall element with a symmetrical cross-section.

composite interaction composite cross-section.

After inserting definition of axial displacements of the sheathing web from Eq. (8) into Eq. (6), Eq. (6) can be rewritten in a more condensed form:

$$
\begin{aligned}
& U\left[u_{1}, u_{2}, u_{3}, \varphi, w\right]=\frac{1}{2} \int_{0}^{L}\left\{E A_{1, \mathrm{sh}} u_{1}^{\prime 2}+E A_{2} u_{2}^{\prime 2}+E A_{3, s h} u_{3}^{\prime 2}+E I_{0} \varphi^{\prime 2}\right. \\
& +K_{\mathrm{s}} G A_{0}\left(\varphi+w^{\prime}\right)^{2} \\
& \left.+k_{1-2}\left(u_{2}-u_{1}-h_{0,1} \varphi\right)^{2}+k_{2-3}\left(u_{3}-u_{2}-h_{0,2} \varphi\right)^{2}\right\} d x-H_{\mathrm{w}} w(L)
\end{aligned}
$$

where

$E A_{3, \mathrm{sh}}=E A_{1, \mathrm{sh}}=E A_{1}+\eta^{2} E A_{\mathrm{sh}, 1-2}$

and $E I_{0}$ is the sum of the bending stiffness of each layer and interlayer (corresponding to a non-composite cross-section), and $G A_{0}$ is the total shear stiffness, and are defined as

$$
\begin{aligned}
& E I_{0}=2 E I_{\mathrm{sh}, 1-2}+\sum_{i=1}^{3} E I_{i} \\
& G A_{0}=2 G A_{\mathrm{sh}, 1-2}+\sum_{i=1}^{3} G A_{i}
\end{aligned}
$$

Thus, the shearing effects of the sheathings are divided into two separate categories: (1) the same conventional shear deformations for all different parts of sheathings (including the parts glued to the framing members and the interlayer ones) as those of the framing members; and (2) the additional shear deformations of the webs modelled as interlayer slips due to the relative axial displacements between the framing layers.

It should be noted that, based on the assumptions of Eq. (12), the total axial stiffness will be changed to a reduced version as follows

$E A_{0, \mathrm{red}}=2 E A_{1, \mathrm{sh}}+E A_{2}=2 \eta^{2} E A_{\mathrm{sh}, 1-2}+\sum_{i=1}^{3} E A_{i}$

\subsection{Governing equations of the model}

Using the minimum total potential energy principle $(\delta U=0)$, the system of governing differential equations are obtained as

$$
\begin{aligned}
& \delta u_{1}: E A_{1, \mathrm{sh}} u_{1}^{\prime \prime}+k\left(u_{2}-u_{1}-h_{0} \varphi\right)=0 \\
& \delta u_{2}: E A_{2} u_{2}^{\prime \prime}+k\left(u_{3}-2 u_{2}+u_{1}\right)=0 \\
& \delta u_{3}: E A_{1, \mathrm{sh}} u_{3}^{\prime \prime}-k\left(u_{3}-u_{2}-h_{0} \varphi\right)=0 \\
& \delta \varphi: E I_{0} \varphi^{\prime \prime}+h_{0} k\left(u_{3}-u_{1}-2 h_{0} \varphi\right)-K_{\mathrm{s}} G A_{0}\left(\varphi+w^{\prime}\right)=0 \\
& \delta w: K_{\mathrm{s}} G A_{0}\left(w^{\prime \prime}+\varphi^{\prime}\right)=0
\end{aligned}
$$

Also, the boundary conditions are determined as follows

$$
\text { at } x=0:\left\{\begin{array}{l}
u_{1}^{\prime} \delta u_{1}=0 \\
u_{2}^{\prime} \delta u_{2}=0 \\
u_{3}^{\prime} \delta u_{3}=0 \\
\varphi^{\prime} \delta \varphi=0 \\
\left(w^{\prime}+\varphi\right) \delta w=0
\end{array}, \text { at } x=L:\left\{\begin{array}{l}
u_{1}^{\prime} \delta u_{1}=0 \\
u_{2}^{\prime} \delta u_{2}=0 \\
u_{3}^{\prime} \delta u_{3}=0 \\
\varphi^{\prime} \delta \varphi=0 \\
{\left[K_{\mathrm{s}} G A_{0}\left(w^{\prime}+\varphi\right)-H_{\mathrm{w}}\right] \delta w=0}
\end{array}\right.\right.
$$

The set of Eqs. (15) and (16) are totally a tenth-order differential equation system and the corresponding boundary conditions at each end.

\subsection{A simplified representation of the governing equations}

An exact equivalent representation of the governing Eq. (15) can be obtained, from doing some mathematical manipulations, as follows

$w^{(5)}-\frac{k}{E A_{1, \mathrm{sh}}} \frac{E I_{\infty}}{E I_{0}} w^{\prime \prime \prime}=\frac{1}{E I_{0}} \frac{k}{E A_{1, \mathrm{sh}}} H_{\mathrm{w}}$

$u_{1}^{\prime \prime \prime}-\frac{k}{E A_{1, \mathrm{sh}}}\left(\frac{E A_{0, \mathrm{red}}}{E A_{2}}\right) u_{1}^{\prime}=\frac{1}{h_{0}} \frac{E I_{0}}{E A_{2}} w^{(4)}-h_{0} \frac{k}{E A_{1, \mathrm{sh}}}\left(\frac{E A_{0, \mathrm{red}}}{E A_{2}}\right) w^{\prime \prime}$

and

$\varphi=-w^{\prime}+\frac{1}{K_{\mathrm{s}}} \frac{H_{\mathrm{W}}}{G A_{0}}$

$u_{2}=-\frac{E A_{1, \mathrm{sh}}}{k} u_{1}^{\prime \prime}+u_{1}+h_{0} \varphi$

$u_{3}=\frac{\left(E A_{2}\right)\left(E A_{1, \mathrm{sh}}\right)}{k^{2}} u_{1}^{(4)}-\frac{E A_{0, \text { red }}}{k} u_{1}^{\prime \prime}+u_{1}-\frac{E A_{2}}{k} h_{0} \varphi^{\prime \prime}+2 h_{0} \varphi$

where $E A_{0, \text { red }}$ is defined by Eq. (14), and $E I_{\infty}$ is the total bending stiffness of the beam corresponding to the full-composite interaction and, using the definition of the coefficient $\eta$ from Eq. (10), is obtained as

$E I_{\infty}=E I_{0}+2 h_{0}^{2} E A_{1, \mathrm{sh}}=E I_{0}+2 h_{0}^{2} E A_{1}+2 h_{\mathrm{sh}}^{2} E A_{\mathrm{sh}}$

It should also be pointed out that the superscript '(i)' over each 
function represents the $i$-th order derivatives of that function with respect to the variable $x$; this notation is applied for the fourth order derivatives and higher, for convenience.

It is noticeable that the original set of tenth-order differential governing Eqs. (15) has been lowered to the eighth-order in the new representation as Eqs. (17). It would be as a result of inserting two of the boundary conditions into the governing equations, which are "the zero axial force", and "the transverse shear load $H_{\mathrm{w}}$ from wind" at the end of the cantilever beam. Details on derivation of the new form of the governing equations are given in Appendix B.

\subsection{Solution of the governing equations}

The complete solution of the governing equations, presented in previous subsection, after satisfaction of the remaining boundary conditions, can be represented as

$$
\begin{aligned}
w & =\frac{H_{\mathrm{W}} L^{3}}{2 E I_{\infty}}\left(1-\frac{x}{3 L}\right)\left(\frac{x}{L}\right)^{2}+\left[\frac{2\left(h_{0} E A_{1, \mathrm{sh}}\right)^{2} H_{\mathrm{W}} L}{k E I_{\infty}^{2}}+\frac{H_{\mathrm{W}} L}{K_{\mathrm{S}} G A_{0}}\right]\left(\frac{x}{L}\right) \\
& -\frac{2\left(h_{0} E A_{1, \mathrm{sh}}\right)^{2} H_{\mathrm{W}} L}{k E I_{\infty}^{2}} \frac{\tanh (\lambda L)}{\lambda L} \\
u_{1} & =-u_{3}=\frac{E I_{I_{0}}}{E I_{\infty}} \frac{h_{0} E A_{1, \mathrm{sh}} H_{\mathrm{W}}}{k E I_{\infty}}\left[\frac{1}{\cosh (\lambda x)}-1\right]+\frac{H_{\mathrm{W}} L^{2} h_{0}}{E I_{\infty}}\left(\frac{x}{L}\right) \\
u_{2} & =0 \\
\varphi & =\frac{2\left(h_{0} E A_{1, \mathrm{sh}}\right)^{2} H_{\mathrm{W}}}{k E I_{\infty}^{2}}\left[\frac{1}{\cosh (\lambda L)}-1\right]-\frac{H_{\mathrm{W}} L^{2}}{E I_{\infty}}\left(1-\frac{x}{2 L}\right)\left(\frac{x}{L}\right)
\end{aligned}
$$

where

$\lambda=\sqrt{\frac{k}{E A_{1, \mathrm{sh}}} \frac{E I_{\infty}}{E I_{0}}}$

Details of the exact closed-form solution procedure are given in Appendix C. It is worth noting that, as it is expected from a physical point of view, the axial displacement of the intermediate framing member, in absence of the external normal force, is zero due to the symmetry in both geometry and constituent materials of the stabilising wall element with respect to its middle plane $\left(u_{2}=0\right)$. Also, as expected, the absolute values of the axial displacements of the upper and lower framing members are identical. i.e., $u_{3}=-u_{1}$. However, they would not be as evident from a mathematical point of view, cf. Eqs. (15) and (17). The mathematical prove of the above-described situation is also given in Appendix C.

\subsection{Calculation of the web interlayer shear stiffness}

Here, a formula is obtained for the shear slip modulus corresponding to the additional relative shear slip at the sheathing web interlayer. To this end, consider a panel of unit length consisting of sheathing webs bounded to the framing layers at its neighbour, subjected to pure shear $\tau_{0}$ as shown in Fig. 6 .

The framing layers and the sheathing interlayers are of thickness $b+2 t$ and $2 t$, respectively, and their equivalent shear modulus can, according to Eqs. (A.7) and (A.8) in Appendix A, be represented as

$G_{\text {eq, }}=\frac{b G_{f}+2 t G_{\text {sh }}}{b+2 t}$

$G_{\text {eq,sh }}=G_{\text {sh }}$

Considering identical shear load between the framing and web with different thicknesses, one can write:

$\frac{\tau_{0}}{\tau}=\frac{2 t}{b+2 t}$

where the geometric dimensions $b$ and $t$ are defined in Fig. 3b. In Eq. (22), $\tau$ is the pure shear stress at sheathing webs. The conventional shear strain of the framing members and the total shear strain of the interlayer web can be expressed as $\tau_{0}$

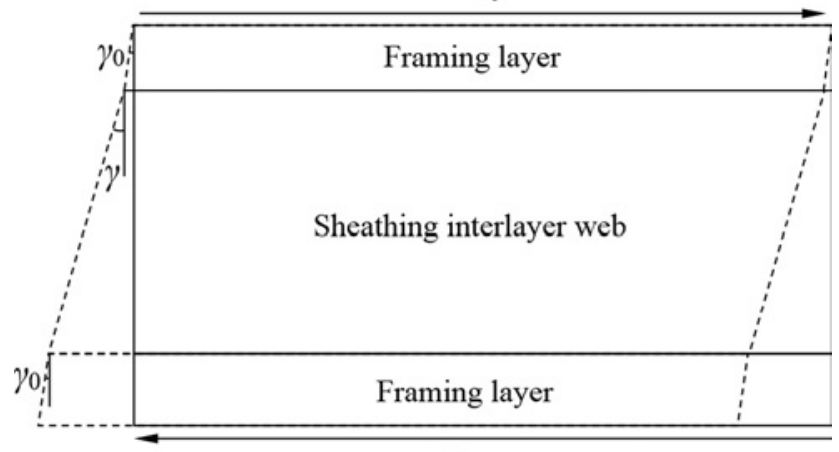

$\tau_{0}$

Fig. 6. A two dimensional model of the sheathing web bounded to framing layers at the neighbour under pure shear.

$\gamma_{0}=\frac{\tau_{0}}{G_{\mathrm{eq}, \mathrm{f}}}$

$\gamma=\frac{\tau}{G_{\mathrm{eq}, \mathrm{sh}}}$

Substituting Eqs. (21) and (22) into Eq. (23) will result in the additional shear strain in the sheathing webs as follows

$\Delta \gamma=\gamma-\gamma_{0}=\frac{b G_{\mathrm{f}}}{G_{\mathrm{sh}}\left(b G_{\mathrm{f}}+2 t G_{\mathrm{sh}}\right)} \tau$

The additional slip between the framing members due to the weak shear web can be represented as

$\Delta u_{\text {slip }}=h_{\mathrm{w}} \Delta \gamma$

Therefore, the slip modulus for the unit horizontal length of the web is obtained as

$k=\frac{2 t \tau}{\Delta u_{\text {slip }}}=\left(1+\frac{2 t G_{\mathrm{sh}}}{b G_{\mathrm{f}}}\right) \frac{2 t}{h_{\mathrm{w}}} G_{\mathrm{sh}}$

Implementation of the obtained slip modulus in conjunction with the solution presented in previous section gives accurate results for weak sheathing web box-type composite beams.

\section{Reliable formulation for the beam deformations}

Using Eqs. (19) and (20) the maximum displacements of the partially composite interacted beam are obtained as follows

$w=\frac{H_{\mathrm{w}} L^{3}}{3 E I_{\infty}}+\frac{1}{K_{\mathrm{s}}} \frac{H_{\mathrm{w}} L}{G A_{0}}+\frac{2\left(h_{0} E A_{1, \mathrm{sh}}\right)^{2}}{k E I_{\infty}^{2}}\left[1-\frac{\tanh (\lambda L)}{\lambda L}\right] H_{\mathrm{w}} L$

$u_{1}=-u_{3}=\frac{h_{0}}{E I_{\infty}}\left\{\frac{1}{2} L^{2}-\frac{E A_{1, s h}}{k} \frac{E I_{0}}{E I_{\infty}}\left[1-\frac{1}{\cosh (\lambda L)}\right]\right\} H_{\mathrm{w}}$

$u_{2}=0$

where the coefficient parameter $\lambda$ is given in Eq. (20). Also, the equivalent slip modulus $k$ of the web interlayers is defined in Eq. (26). Indeed, Eq. (27.1) together with Eq. (26) gives a realistic prediction of deflection of such deep box-type beams without needing to unusual magnification/shear correction factors. The described concept in this paper can be used for any different types of deep beams having special cross-section shapes, especially those having weak shear webs. The first and second terms of Eq. (27.1) represent deflections due to the bending deformations and conventional in-plane shear deformations within the framing and sheathing layers, respectively, whereas the third term exhibits the additional shear deformations in the sheathing webs. Therefore, structural engineers can simply use Eq. (27.1) for a reliable deflection prediction of such types of beams without the need of using an unusual proprietary shear correction/magnification factor. It will be shown in the next section that the third term of Eq. (27.1) will cause a very small overestimation of the deformation of the beam which will 
put the engineers' calculation on the safe side based on the serviceability limit state design.

To examine the correctness of the achieved deflection by Eq. (27.1), two known extreme cases are considered, namely, full-composite and non-composite beams.

\subsection{Lower bound: full-composite interaction between the framing members}

It is expected to obtain the solution of a composite cantilever beam with three perfectly bounded layers based on the Timoshenko theory when the shear stiffness between the layers approaches infinity. To evaluate it, the following limitations are calculated

$\lim _{k \rightarrow \infty} w=\frac{H_{\mathrm{w}} L^{3}}{3 E I_{\infty}}+\frac{1}{K_{\mathrm{s}}} \frac{H_{\mathrm{w}} L}{G A_{0}}$

$\lim _{k \rightarrow \infty} u_{1}=-\lim _{k \rightarrow \infty} u_{3}=\frac{h_{0} H_{\mathrm{w}} L^{2}}{2 E I_{\infty}}$

Clearly, Eqs. (28) are exactly the same as the static solution for a three-layer perfectly bonded composite cantilever beam subjected to a shear point load $\left(H_{\mathrm{w}}\right)$.

\subsection{Upper bound: non-composite interaction between the framing members}

In the case of non-composite interaction, the shear slip modulus between the layers of composite beam $(k)$ should approach zero. i.e.,

$\lim _{k \rightarrow 0} w=\frac{H_{\mathrm{w}} L^{3}}{3 E I_{0}}+\frac{1}{K_{\mathrm{s}}} \frac{H_{\mathrm{w}} L}{G A_{0}}$

$\lim _{k \rightarrow 0} u_{1}=\lim _{k \rightarrow 0} u_{3}=0$

In this case, as expected, the axial displacement components $\left[u_{1}, u_{2}, u_{3}\right]$ of the beam become zero. Also, the deflection formula is converted to that for the deflection of three separate parallel beams together with sheathings based on Timoshenko theory.

\section{Numerical results and discussion}

Based on the previously described analysis and solutions, some numerical results and a discussion are conducted. For generality of the numerical results and convenience, the following dimensionless parameters are introduced:

$\bar{h}_{1}=h_{1} / h, \bar{h}_{2}=h_{2} / h, \bar{t}=t / b, \bar{L}=L / h, \bar{E}=E_{\mathrm{sh}} / E_{\mathrm{f}}$

$\bar{G}=G_{\mathrm{sh}} / G_{\mathrm{f}}, \psi=E_{\mathrm{f}} / G_{\mathrm{f}}, \bar{w}_{\max }=\left(E_{\mathrm{f}} b / H_{\mathrm{w}}\right) w_{\max }$

Eq. (30) provides a complete set of the dimensionless parameters. It is noticeable that, for the numerical results, the mechanical and geometric values of the Trä8 stabilising wall element are utilized as the reference values:

$E_{\mathrm{f}}=12600 \mathrm{MPa}, \quad E_{\mathrm{sh}}=10500 \mathrm{MPa}$

$G_{\mathrm{f}}=720 \mathrm{MPa}, \quad G_{\mathrm{sh}}=600 \mathrm{MPa}$

$t=27 \mathrm{~mm}, b=160 \mathrm{~mm}, h_{1}=h_{3}=360 \mathrm{~mm}$,

$h_{2}=225 \mathrm{~mm}, h=2400 \mathrm{~mm}, L=6000 \mathrm{~mm}$

Unless mentioned otherwise, the above reference values are used for the presented numerical results.

It was shown in the previous section that, for a deep box-type beam with weak shear webs, three distinguished phenomena play role in determining the deflection: (1) normal bending deformations; (2) conventional transverse shear deformations in the framing layers and the interlayer sheathings; and (3) the additional in-plane shear deformations in sheathing web modelled as interlayer slip. Therefore, apart from presenting some graphs for the variation of the deflection versus some effective geometric and material properties, some figures are presented to investigate the influence on each type of deformations on the deflection for each effective geometric and material parameter. In

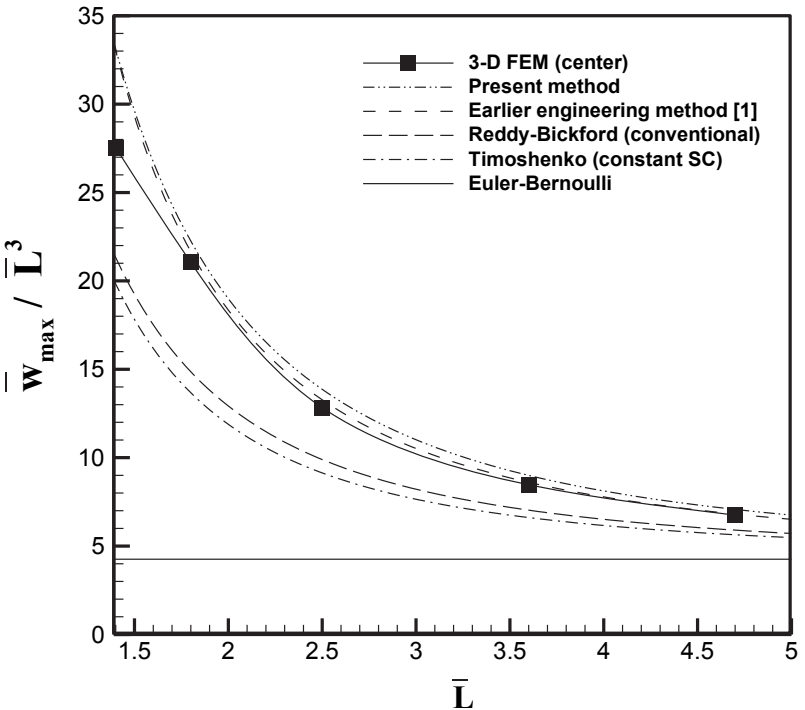

(a)

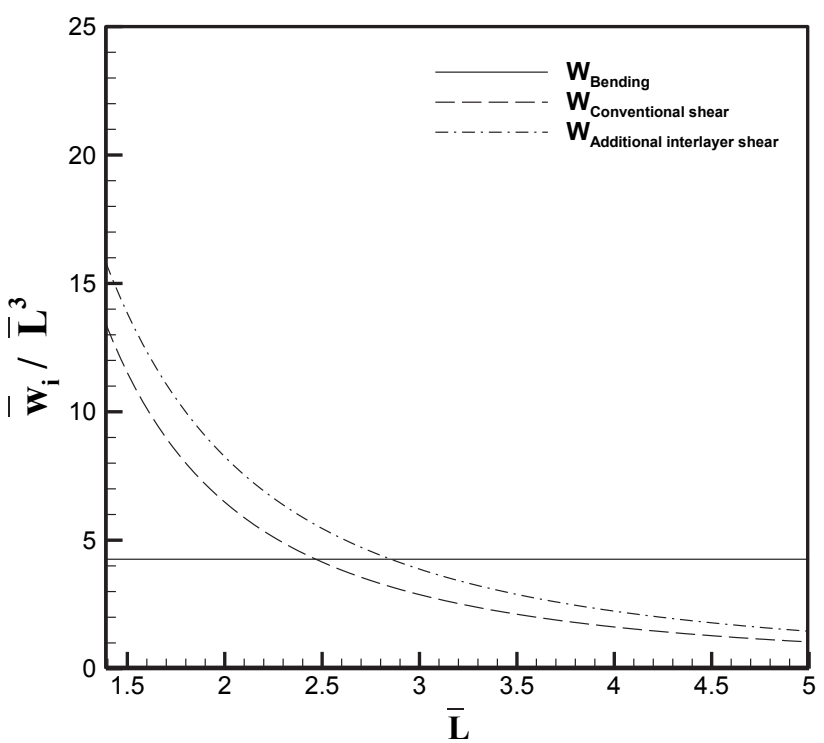

(b)

Fig. 7. Variations of (a) dimensionless deflection parameter $\left(\bar{w}_{\max } / \bar{L}^{3}\right)$, and (b) the different triple deformation types, vs. the length-to depth ratio $(\bar{L}=L / h)$.

all figures, the results of the conventional theories of Euler-Bernouli, Timoshenko and Reddy-Bickford (with the shear variation corresponding to a rectangular cross-section) are provided as well as the corresponding results based on an engineering method presented in Girhammar and Atashipour [1]. Also, several accurate 3-D finite element simulations have been performed for all cases using ANSYS software to examine the accuracy of different approaches, comparatively. The FE models are meshed using the solid element type "Brick 20node 186". The nodes at the interfaces are tied to apply perfect bonding condition between the sheathings and glulam framing members. Full displacement constraints are imposed on all the nodes of one end surface. The transverse tip load is applied through a uniformly distributed shear load over the cross-section at the other beam end.

Fig. $7 \mathrm{a}, \mathrm{b}$ shows variation of the dimensionless deflection parameter, and the effect of the different triple types of the deformations versus the dimensionless length of the beam element based on different approaches together with the method presented in this paper. It should be pointed out that the dimensionless deflection in this figure has been 
divided by $\bar{L}^{3}$ to make the bending deformations (equivalent to the Euler-Bernoulli results) independent of the dimensionless length. It can be seen from Fig. 7a that the results of the present approach and the engineering method of Girhammar and Atashipour [1] are in good agreement with those based on the accurate 3-D simulations. Although, the theories of Reddy-Bickford and Timoshenko with constant shear correction factor (the abbreviation "constant SC" is used in figures) include the shear deformations, they do not model the dominant additional shear deformations in the sheathings (acting as web). Therefore, they highly underestimate the deflection whereas the Euler-Bernoulli results are very weak for such deep box-type beams. To demonstrate the effect of the different triple types of the deformations, Fig. 7b is depicted based on the present method. It is seen that the effect of bending deformations will be more dominant by increasing the length-to-depth ratio of the beam. For short beams with the length-todepth ratio less than about 2.5 to 3 , the influence of both the shear deformations in the beam and the additional shear deformations at the sheathing interlayers are more dominant than the bending deformations.

Variations of the dimensionless deflection together with variations of the different triple deflection types versus the geometric parameter $h_{1} / h$ are illustrated in Fig. 8a and b, respectively. It should be pointed out that the beginning point of each curve in Fig. 8a, b shows a beam cross-section without the upper/lower framing members (i.e. $h_{1}=0$ ) whereas the end point of the curves represents a beam with full solid cross-section (without the sheathing webs and the slip). Therefore, as it is expected, the interlayer slip effect vanishes at the end points of both Fig. 8a, b. It can be seen from Fig. 8a that the results of the present method are in good agreement with those of engineering approach in Girhammar and Atashipour [1] and the 3-D FE results. Also, it is seen that the results of all shear deformable models (i.e. all methods excluding the Euler-Bernoulli theory) approximately approach each other when the beam cross-section becomes fully solid; because, the effect of the interlayer shear slip disappears in this case. Also, it is seen that the effect of bending deformations on the deflection greatly increases by decreasing the height of the upper-lower framing layers (i.e. increasing the height of the web). Obviously, this is due to the fact that the upper/ lower framing members have considerable influence on the bending stiffness of the beam.

Similar to Fig. 8a and b, some curves are provided in Fig. 9a and b for the geometric parameter $h_{2} / h$ to study the influence of the height of the intermediate framing layers on the maximum deflection of the beam. Comparing the results of different methods with those of the 3-D solutions reveals that the present method gives acceptable predictions for the static elastic analysis of such deep box-type beams with weak shear webs. However, the results of the earlier engineering method [1] seem to be more accurate than those based on the present method for the timber range of geometry and property parameters whereas other conventional beam theories (for rectangular-type of cross-sections) are not reliable. It can be seen form Fig. 9a that the maximum deflection slightly decreases when the height of the intermediate framing layer increases. It is noted that the end points of the curves in Fig. 9a, b are corresponding to a fully solid cross-section case without any interlayer webs. Therefore, the effect of the relative displacement at interlayers due to web shear deformations on the maximum deflection tends to zero by increasing the height of the intermediate framing member to its maximum size, as shown in Fig. 9b. Also, it can be observed that the effects of both bending deformations and the conventional shear deformations in the beam on the deflection slightly decrease by increasing the height of the intermediate framing member.

Fig. 10a shows variations of dimensionless deflection versus the mechanical parameter, $E_{\mathrm{sh}} / E_{\mathrm{f}}$. Also, variations of different triple deflection types are illustrated in Fig. 10b. It can be observed that the results of the present method are in good agreement with those of the earlier engineering method [1] and the 3-D FE simulation results. However, the present method overestimates the deflection of the

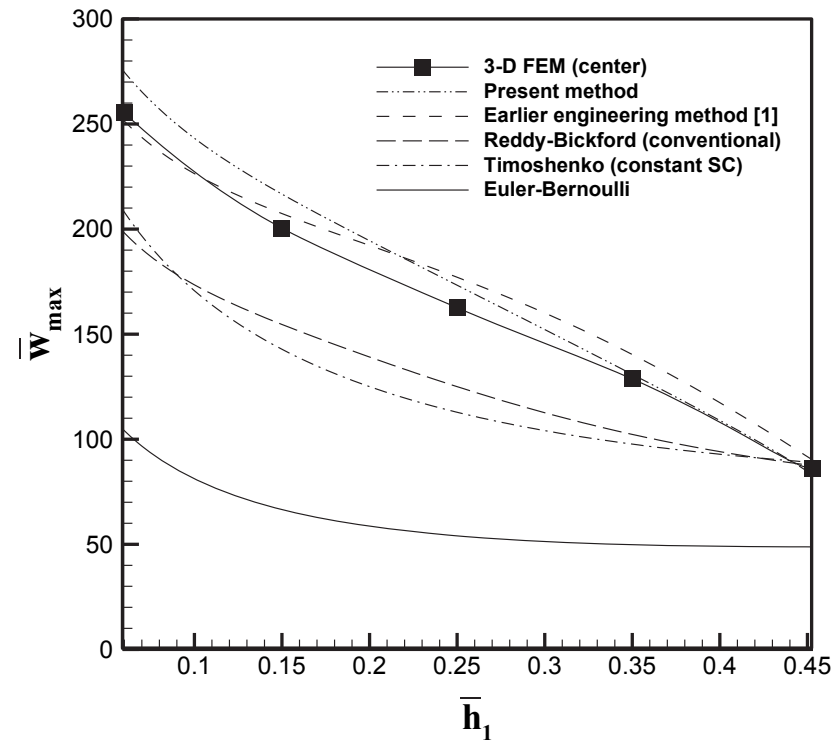

(a)

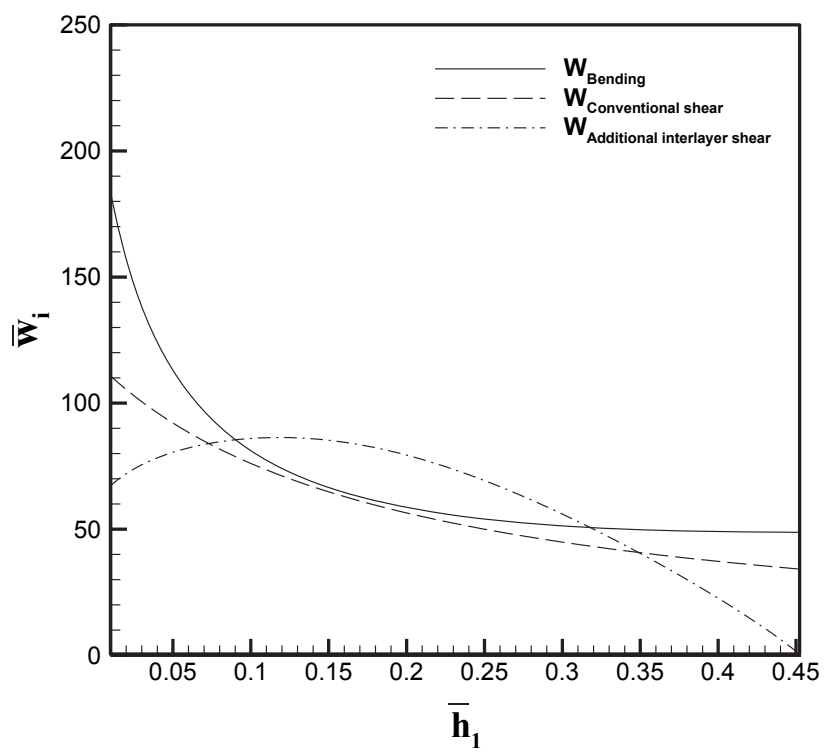

(b)

Fig. 8. Variations of (a) dimensionless deflection, and (b) the different triple deformation types, vs. the geometric parameter $\bar{h}_{1}=h_{1} / h$.

structure. Obviously, the results of other conventional theories are inaccurate for such box-type beam with weak shear webs. It is seen from Fig. $10 \mathrm{~b}$ that the Young's modulus ratio, $E_{\mathrm{sh}} / E_{\mathrm{f}}$, does not affect the shear deformations in the framing members and it has a weak effect on the deflection due to the relative displacement of the frames at the interlayers.

Fig. $11 \mathrm{a}$ and b provide the effect of shear modulus ratio, $G_{\mathrm{sh}} / G_{\mathrm{f}}$, on the maximum dimensionless deflection and the triple deflection types, respectively. Comparison of the curves of Fig. 11a reveals a very good agreement between the results of the present method and those of the former study [1] and the 3-D FE simulations. It can be seen from Fig. $11 \mathrm{~b}$ that increasing the shear modulus ratio will result in a decrease in the maximum deflection of the structure. Although the conventional theories of Reddy-Bickford and Timoshenko with constant SC factor predicts the similar trend behaviour, their error increases by decreasing the shear modulus ratio. Clearly, this parameter does not affect the 


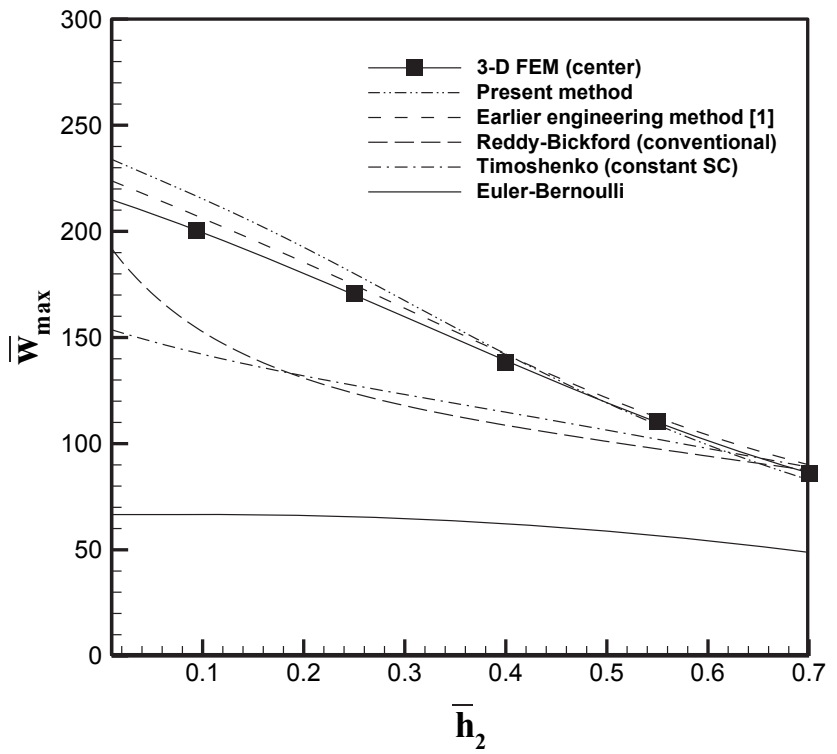

(a)

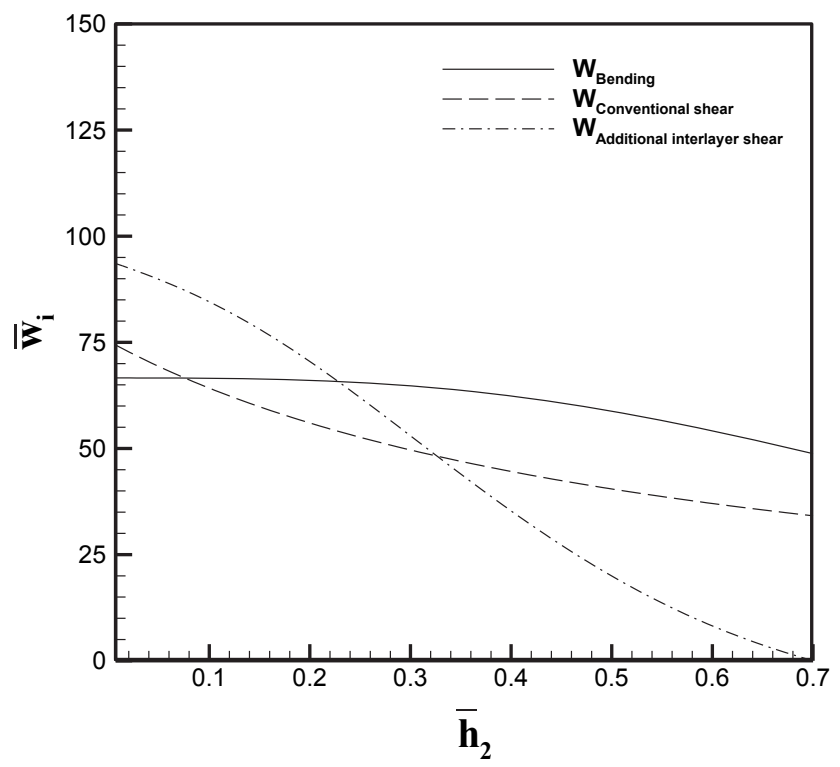

(b)

Fig. 9. Variations of (a) dimensionless deflection, and (b) the different triple deformation types, vs. the geometric parameter $\bar{h}_{2}=h_{2} / h$.

bending deformations (i.e. the Euler-Bernoulli theory). Also, the curves of Fig. 11b reveals that the influence of the shear modulus ratio on the deflection due to the relative displacement of framing at the interlayers is more dominant than that on the shear deformations in the framing layers.

It is worth noting that the established model in this paper minorly overpredicts the deflection compared to the results of 3-D FE simulations, as it can be seen from Figs. 7-11. This may be due to the fact that a reduced version of the total axial stiffness is incorporated in the developed model. Such approximate assumption is essential to avoid inefficient mathematically-complicated formulation. Obviously, this assumption would be reasonable for the box beams especially those with thin/weak webs. On the other hand, the minor overprediction of deformations put the engineers' calculation on the safe side based on the serviceability limit state design.

In order to study the effect of mechanical properties of the web on

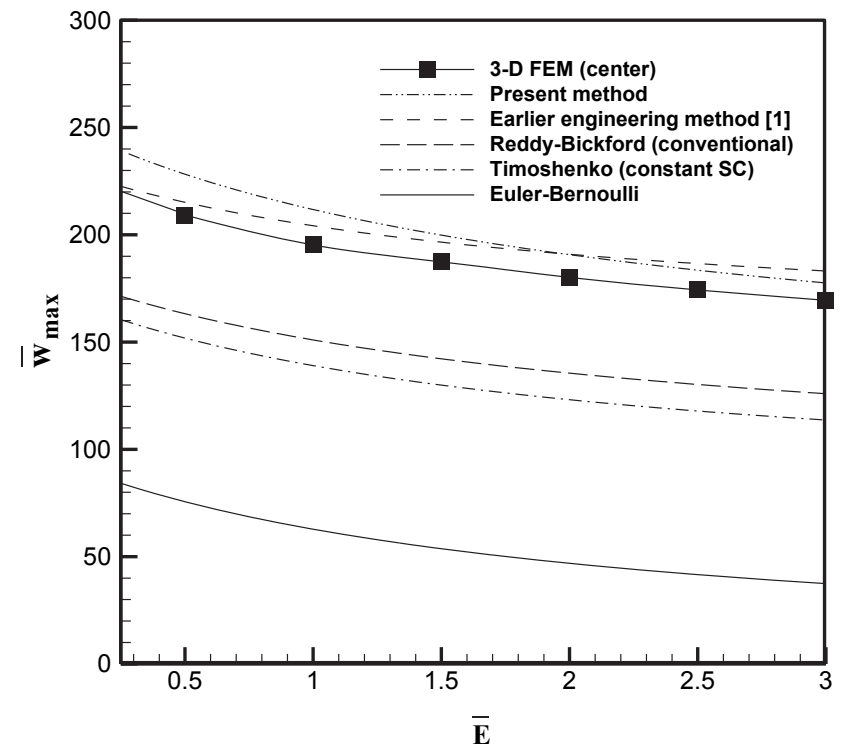

(a)

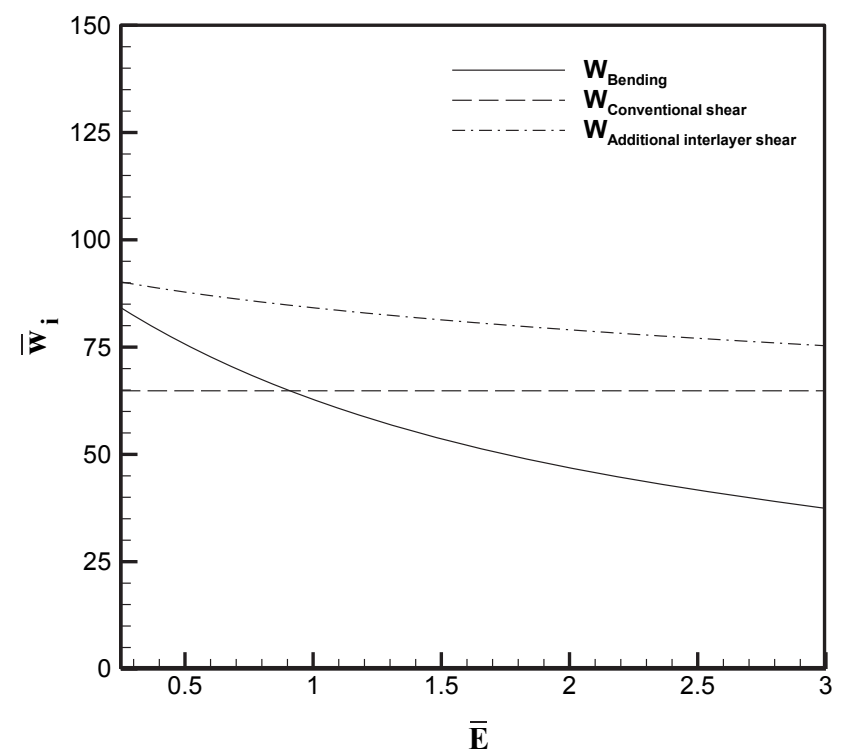

(b)

Fig. 10. Variations of (a) dimensionless deflection, and (b) the different triple deformation types, vs. the material parameter $\bar{E}=E_{\mathrm{sh}} / E_{\mathrm{f}}$.

the interaction of the structural element layers, Fig. 12 is presented for variations of the dimensionless deflection versus the dimensionless modulus ratio $\bar{G}=\bar{E}$, based on different methods. This parameter $\bar{G}=\bar{E}$ expresses the fact that the shear and elasticity moduli vary simultaneously. This figure is given in a semi-logarithmic scale to investigate the effect of two extreme cases corresponding to rigid sheathings and removed sheathings. As mentioned earlier the maximum deflection according to the box-type model [1] tends to infinity for small values of the web shear stiffness, while the present equivalent slip-type or sandwich-type of model gives finite asymptotic values for both high and low extreme values. The latter model agrees well with the 3-D finite element results, especially for small stiffness values.

In a regular sandwich construction, the faces are interacting with one another (the so called sandwich effect) through the core (glued to the faces) even if the stiffness tends to zero (the flexural rigidity of the sandwich consists mainly of the stiffness of the faces associated with the bending about the centroidal axis of the entire sandwich). The 


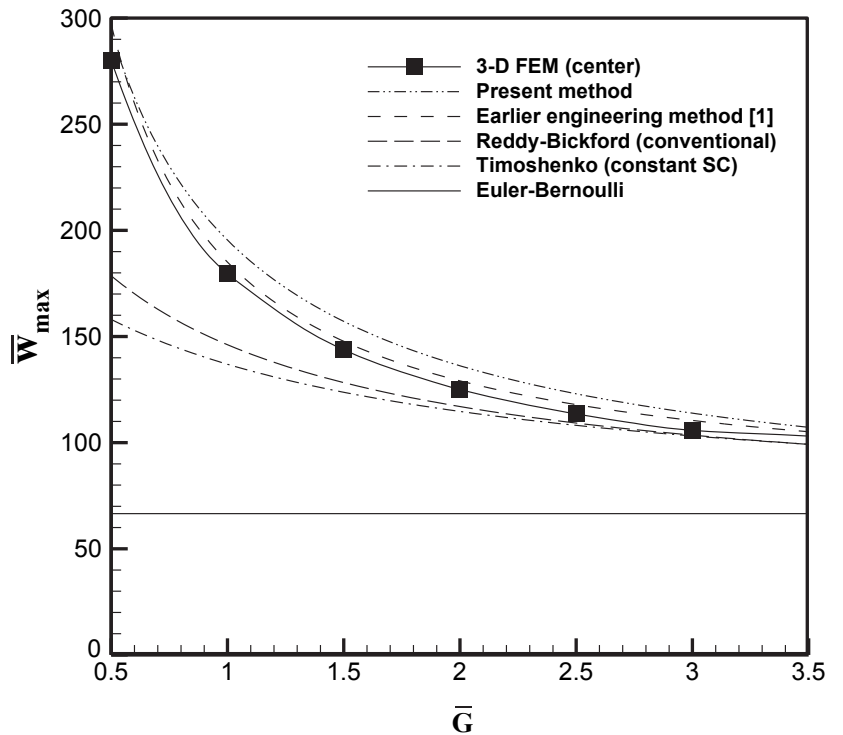

(a)

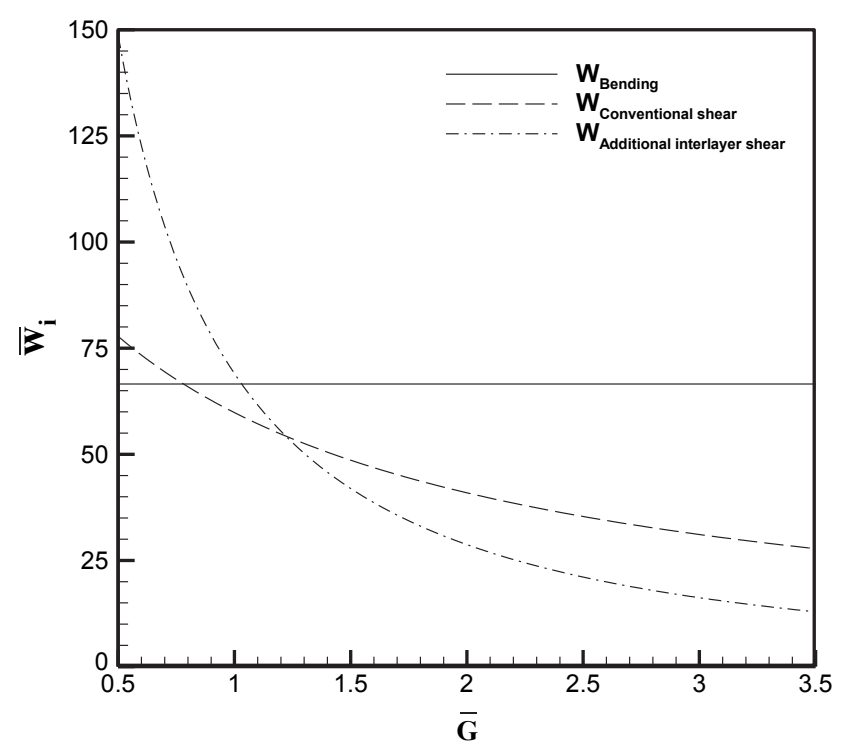

(b)

Fig. 11. Variations of (a) dimensionless deflection, and (b) the different triple deformation types, vs. the material parameter $\bar{G}=G_{\mathrm{sh}} / G_{\mathrm{f}}$.

parameters for sandwich beams are usually in the order of $0.001<G_{2}$ / $G_{1}=E_{2} / E_{1}<0.02$. It is to be expected that the agreement between results of the equivalent slip-type model and the 3-D finite element analysis would be also very good for thin faces as is usually used in sandwich beams (the ratio is of the order of $0.02<h_{\text {face }} / h_{\text {core }}<0.1$ ).

For wooden box-type of beams the practical parameter range is of the order of $0.1<G_{2} / G_{1}=E_{2} / E_{1}<3$. A detailed graph in that range is shown in Fig. 12. The practical example of Trä8 $\left(G_{2} / G_{1}=E_{2} /\right.$ $E_{1}=0.833$ ) falls within this range. In that range the present slip-type model, like the box-type model, gives close results compared to the 3-D finite element analysis (Fig. 13). Also, the results of Euler-Bernoulli, Timoshenko theory with constant correction factor for a rectangular cross-section and Reddy-Bickford models (corresponding to a rectangular cross-section) are illustrated for comparison reasons. It can be seen that the predicted results by these conventional theories are very far from the 3-D results and they are as expected not suitable for the elements like the Trä8 stabilising wall element.

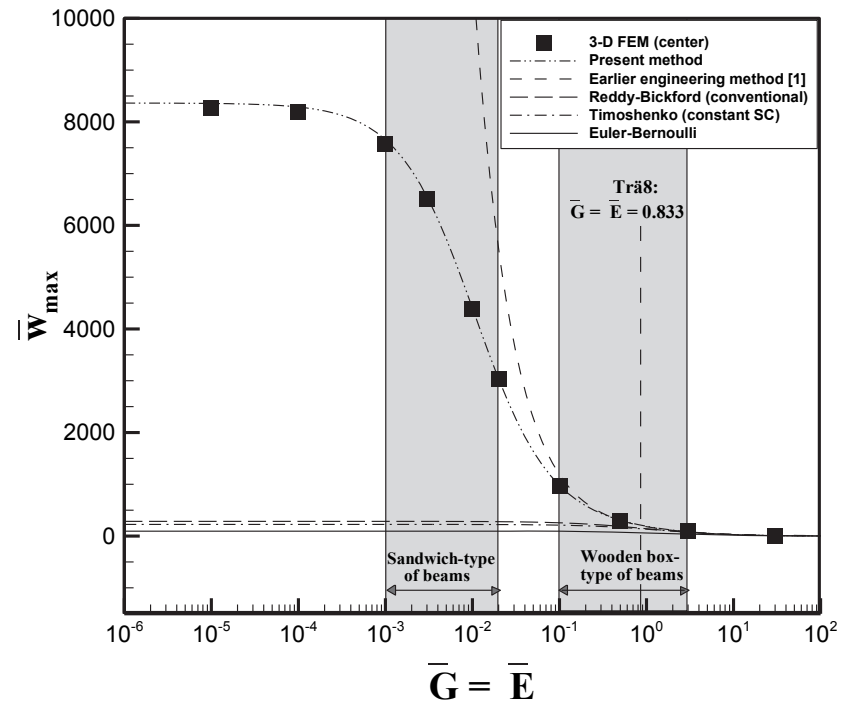

Fig. 12. Variations of dimensionless deflection vs. the material properties.

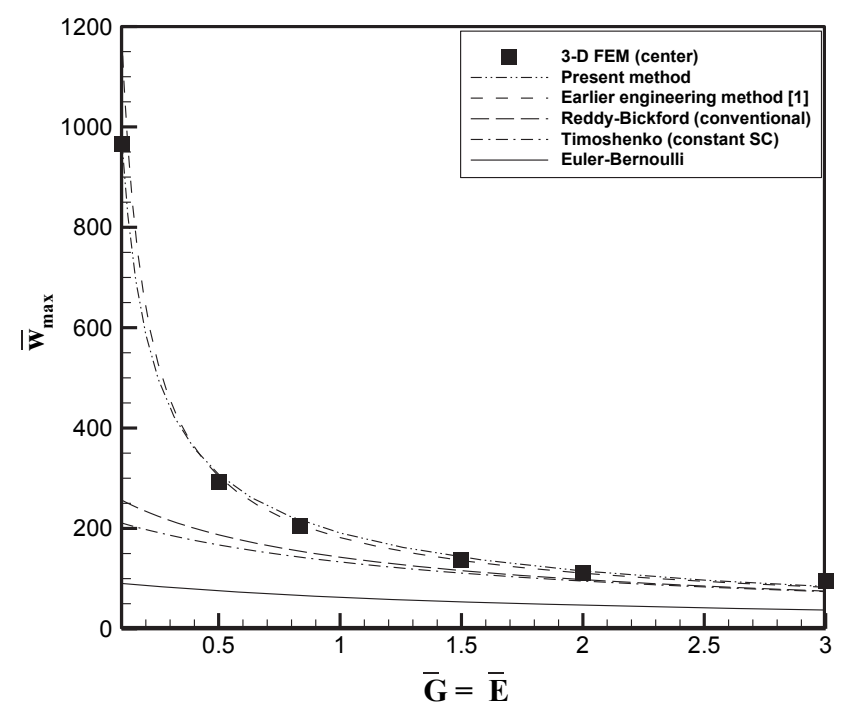

Fig. 13. Variations of dimensionless deflection vs. the material properties for the "wooden box-type beam" range.

\section{Conclusions}

In the present study, a new simple model was established for the static deformation of deep composite box-type beams; especially for the structures with weak sheathing webs. The minimum total potential energy principle was utilized to obtain the governing equilibrium equations and boundary conditions. Thin sheathings between the framing members were considered as webs in shear and an equivalent slip due to their weakness were incorporated into the governing equations. It was shown that three phenomena play important role in determining the deflection of such deep box-type beams: (1) bending deformations; (2) conventional shear deformations in the framing layers and the sheathings; and (3) the additional shear deformations between the framing layers due to the weakness of the sheathing modelled as shear slip. It was shown that for such deep box beams, neglecting the slip effects causes large errors in the prediction of the deflection for weak shear webs. It was proven that, unlike the predicted deflection according to the box-type model [1] which tends to infinity for small values of the web shear stiffness, the present modified model can accurately predict the deformations for any arbitrary ranges of geometrical and material property parameters including the property 


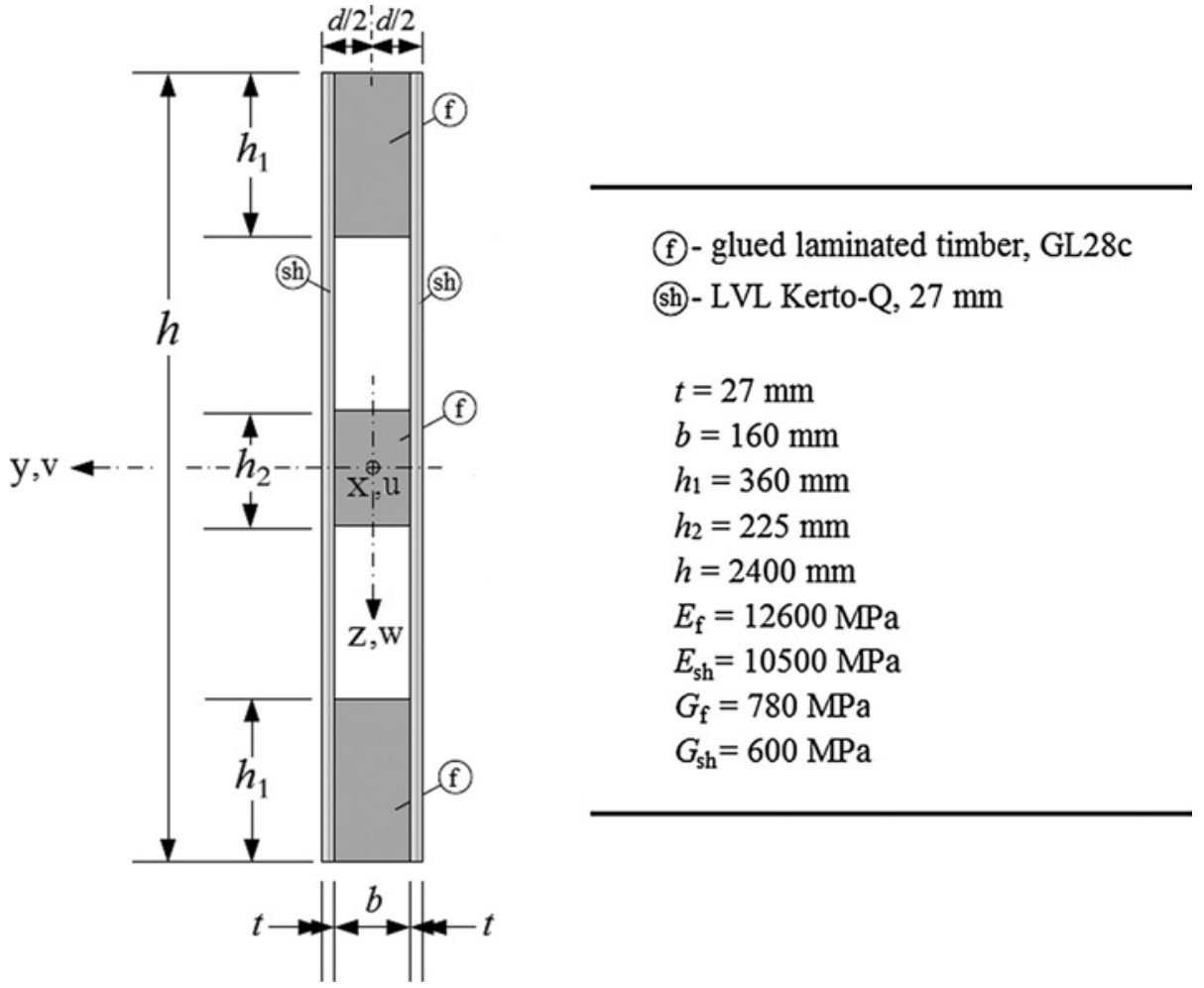

Fig. A1. The symmetric cross-section of the Trä8 wall panel comprised of two materials: (a) framing members (subscript ' $\mathrm{f}$ ') and (b) sheathing (subscript 'sh').

ranges for "wooden box-type beams". It was also demonstrated that addition of such a third term, based on the concept introduced in this paper, to the conventional beam deflection formulae would result in accurate deflection prediction for beams with abrupt geometrical variations in cross-section, like box beams, without need of using a particular magnification/shear correction factor.

\section{Acknowledgements}

The authors would like to express their sincere appreciation for the financial support from the Regional Council of Västerbotten, the County Administrative Board in Norrbotten, and the European Union: European Regional Development Fund - Regional Structural Fund and Interregional Programmes.

\section{Appendix A. Illustration of the shear correction factor evaluation for the Trä8 wall panel}

The cross-section of the Trä8 wall panel, the notations and the parameter values are shown in Fig. A.1.

To evaluate Eq. (3), the integration is divided into three parts of the height of the cross-section as shown in Fig. A.2. Due to the symmetry, only half of the cross-section is considered.

$1 / K_{\mathrm{s}}=\frac{2 G A_{0}}{E I_{\infty}^{2}}\left\{\int_{0}^{h_{2} / 2} \frac{\left[E S_{\mathrm{I}}(z)\right]^{2}}{G_{\mathrm{eq}, \mathrm{I}} d_{\mathrm{I}}} \mathrm{d} z+\int_{h_{2} / 2}^{h / 2-h_{1}} \frac{\left[E S_{\mathrm{II}}(z)\right]^{2}}{G_{\mathrm{eq}, \mathrm{II}} d_{\mathrm{II}}} \mathrm{d} z+\int_{h / 2-h_{1}}^{h / 2} \frac{\left[E S_{\mathrm{III}}(z)\right]^{2}}{G_{\mathrm{eq}, \mathrm{III}} d_{\mathrm{III}}} \mathrm{d} z\right\}$

where

$G A_{0}=2 G_{\mathrm{f}} b h_{1}+G_{\mathrm{f}} b h_{2}+2 G_{\mathrm{sh}} t h=2 G A_{1}+G A_{2}+2 G A_{\mathrm{sh}, 1-2}$

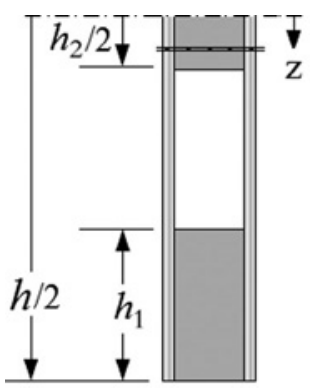

$0 \leq z \leq h_{2} / 2$

(I)

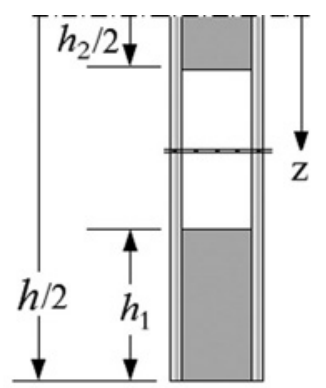

$$
h_{2} / 2 \leq z \leq h / 2-h_{1}
$$

(II)

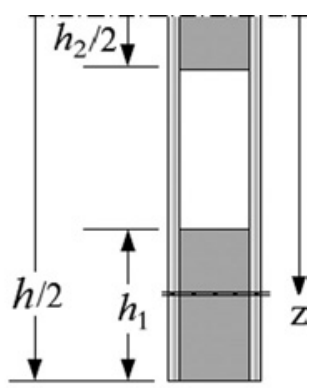

Fig. A2. The different parts or levels of the symmetric crosssection for determining the shear correction factor. 


$$
\begin{aligned}
E I_{\infty} & =2 E_{\mathrm{f}}\left\{\frac{1}{12} b h_{1}^{3}+b h_{1}\left[\frac{1}{2}\left(h-h_{1}\right)\right]^{2}\right\}+E_{\mathrm{f}}\left(\frac{1}{12} b h_{2}^{3}\right)+2 E_{\mathrm{sh}}\left(\frac{1}{12} t h^{3}\right) \\
& =2 E I_{1}+E I_{2}+2 E I_{\mathrm{sh}, 1-2}+2 h_{0}^{2} E A_{1}+2 E A_{\mathrm{sh}, 1-2} h_{\mathrm{sh}}^{2}
\end{aligned}
$$

$E S_{\mathrm{I}}(z)=\frac{1}{2}\left[E_{\mathrm{f}} b h_{1}\left(h-h_{1}\right)+E_{\mathrm{f}} b\left(\frac{h_{2}}{2}-z\right)\left(\frac{h_{2}}{2}+z\right)+2 E_{\mathrm{sh}} t\left(\frac{h}{2}-z\right)\left(\frac{h}{2}+z\right)\right]$

$$
=E A_{1} h_{0}+E A_{\mathrm{sh}, 1-2} h_{\mathrm{sh}}+\frac{1}{8} E A_{2} h_{2}\left[1-\left(\frac{2 z}{h_{2}}\right)^{2}\right]
$$

$E S_{\text {II }}(z)=\frac{1}{2} E_{\mathrm{f}} b h_{1}\left(h-h_{1}\right)+E_{\mathrm{sh}} t\left(\frac{h}{2}-z\right)\left(\frac{h}{2}+z\right)$

$$
=E A_{1} h_{0}+\frac{1}{8} E A_{\mathrm{sh}, 1-2} h_{\mathrm{w}}\left(2+\frac{h_{2}}{h_{\mathrm{w}}}\right)^{2}\left[1-\left(\frac{2 z}{2 h_{\mathrm{w}}+h_{2}}\right)^{2}\right]
$$

$E S_{\text {III }}(z)=\frac{1}{2}\left(E_{\mathrm{f}} b+2 E_{\mathrm{sh}} t\right)\left(\frac{h}{2}-z\right)\left(\frac{h}{2}+z\right)=\frac{1}{8} E A_{1} \frac{h^{2}}{h_{1}}\left[1-\left(\frac{2 z}{h}\right)^{2}\right]$

$G_{\mathrm{eq}, \mathrm{I}}=\frac{G_{\mathrm{f}} b+2 G_{\mathrm{sh}} t}{b+2 t}=G_{\mathrm{eq}, \mathrm{III}}$

$G_{\mathrm{eq}, \mathrm{II}}=\frac{2 G_{\mathrm{sh}} t}{2 t}=G_{\mathrm{sh}}$

$d_{\mathrm{I}}=b+2 t=d_{\mathrm{III}}$

$d_{\mathrm{II}}=2 t$

It is observed from Eqs. (A.7)-(A.10) that the equivalent shear stiffness per unit length in the z-direction is given by $G_{\text {eq }, n} d_{n}=\sum_{n} G_{n} d_{n}$ at respective $z$-level. Using these expressions in Eq. (A.1) and integrating finally gives the shear correction factor as $1 / K_{\mathrm{s}}=2.17$, when the parameters in Fig. A.1 for the Trä8 element is used.

\section{Appendix B. Derivation of the new representation of the governing equations}

The order of the differential equation can be lowered if the boundary conditions for the normal force are used. To this end, we add the three first of Eq. (15) and obtain

$E A_{1, \mathrm{sh}} u_{1}^{\prime \prime}+E A_{2} u_{2}^{\prime \prime}+E A_{1, \mathrm{sh}} u_{3}^{\prime \prime}=0$

Integrating Eq. (B.1) one time results in the definition of the total normal force that must set to zero since the stabilising wall element is only subjected to a transverse shear force from wind; therefore,

$N_{\text {total }}=E A_{1, \mathrm{sh}} u_{1}^{\prime}+E A_{2} u_{2}^{\prime}+E A_{1, \mathrm{sh}} u_{3}^{\prime}=c_{1}=0$

Also, the Shear force boundary condition (i.e. the last of Eq. (16) at $x=L$ ) is valid through the entire structure and can be substituted into the fourth of Eq. (15). Consequently, this equation is simplified as

$E I_{0} \varphi^{\prime \prime}+h_{0} k\left(u_{3}-u_{1}-2 h_{0} \varphi\right)=H_{\mathrm{w}}$

Also, by integrating the last of Eq. (15) and satisfying the transverse shear force boundary condition we have

$K_{\mathrm{s}} G A_{0}\left(w^{\prime}+\varphi\right)=c_{2}=H_{\mathrm{w}}$

Now, the original set of governing Eqs. (15) can be replaced by a reduced set of eighth-order differential equations in the form

$$
\begin{aligned}
& E A_{1, \mathrm{sh}} u_{1}^{\prime \prime}+k\left(u_{2}-u_{1}-h_{0} \varphi\right)=0 \\
& E A_{2} u_{2}^{\prime \prime}+k\left(u_{3}-2 u_{2}+u_{1}\right)=0 \\
& E A_{1, \mathrm{sh}} u_{1}^{\prime}+E A_{2} u_{2}^{\prime}+E A_{1, \mathrm{sh}} u_{3}^{\prime}=0 \\
& E I_{0} \varphi^{\prime \prime}+h_{0} k\left(u_{3}-u_{1}-2 h_{0} \varphi\right)=H_{\mathrm{w}} \\
& K_{\mathrm{s}} G A_{0}\left(w^{\prime}+\varphi\right)=H_{\mathrm{w}}
\end{aligned}
$$

The set of Eq. (B.5) can be recast into a set of uncoupled equations. To this end, we utilize the first and second of Eq. (B.5), and express $u_{2}$ and $u_{3}$ in terms of $u_{1}, \varphi$ and their derivatives as follows

$$
\begin{aligned}
& u_{2}=-\frac{E A_{1}, \mathrm{sh}}{k} u_{1}^{\prime \prime}+u_{1}+h_{0} \varphi \\
& u_{3}=\frac{\left(E A_{2}\right)\left(E A_{1}, \mathrm{sh}\right)}{k^{2}} u_{1}^{(4)}-\frac{E A_{0, \text { red }}}{k} u_{1}^{\prime \prime}+u_{1}-\frac{E A_{2}}{k} h_{0} \varphi^{\prime \prime}+2 h_{0} \varphi
\end{aligned}
$$

where $E A_{0, \text { red }}$ is defined by Eq. (14). Substituting Eq. (B.6) into the third and fourth of Eq. (B.5) results in a set of two equations in terms of $u_{1}$ and $\varphi$ only:

$$
\begin{aligned}
& \left(\frac{E A_{1, \mathrm{sh}}}{k}\right)^{2} u_{1}^{(5)}-2 \frac{E A_{1, \mathrm{sh}}}{k}\left(1+\frac{E A_{1, \mathrm{sh}}}{E A_{2}}\right) u_{1}^{\prime \prime \prime}+\left(\frac{E A_{0, \mathrm{red}}}{E A_{2}}\right) u_{1}^{\prime}-h_{0} \frac{E A_{1, \mathrm{sh}}}{k} \varphi^{\prime \prime \prime}+h_{0}\left(\frac{E A_{0, \mathrm{red}}}{E A_{2}}\right) \varphi^{\prime}=0 \\
& h_{0} \frac{\left(E A_{1, \mathrm{sh}}\right)}{k} u_{1}^{(4)}-h_{0}\left(\frac{E A_{0, \mathrm{red}}}{E A_{2}}\right) u_{1}^{\prime \prime}+\left(\frac{E I_{0}}{E A_{2}}-h_{0}^{2}\right) \varphi^{\prime \prime}=\frac{H_{\mathrm{w}}}{E A_{2}}
\end{aligned}
$$


Now, we differentiate Eq. (B.8) one time, and eliminate $(E A / k)^{2} u_{1}^{(5)}$ from Eq. (B.7), which results in the following equation:

$-h_{0} \frac{E A_{1, \mathrm{sh}}}{k} u_{1}^{\prime \prime \prime}+h_{0}\left(\frac{E A_{0, \mathrm{red}}}{E A_{2}}\right) u_{1}^{\prime}-\frac{E A_{1}}{k}\left(\frac{E I_{0}}{E A_{2}}\right) \varphi^{\prime \prime \prime}+h_{0}^{2}\left(\frac{E A_{0, \mathrm{red}}}{E A_{2}}\right) \varphi^{\prime}=0$

Differentiating Eq. (B.9) one time and subtracting the results from Eq. (B.8) yields an uncoupled equation in terms of $\varphi$ only as follows

$\varphi^{(4)}-\frac{k}{E A_{1, \mathrm{sh}}} \frac{E I_{\infty}}{E I_{0}} \varphi^{\prime \prime}=-\frac{1}{E I_{0}} \frac{k}{E A_{1, \mathrm{sh}}} H_{\mathrm{w}}$

where $E I_{\infty}$ is the total bending stiffness of the beam corresponding to the full-composite interaction and, using the definition of the coefficient $\eta$ from Eq. (10), is obtained as

$E I_{\infty}=E I_{0}+2 h_{0}^{2} E A_{1, \mathrm{sh}}=E I_{0}+2 h_{0}^{2} E A_{1}+2 h_{\mathrm{sh}}^{2} E A_{\mathrm{sh}}$

Eq. (B.10) can be rewritten in terms of the transverse deflection. To this end we differentiate the fifth of Eq. (B.5) and obtain:

$\varphi^{\prime}=-w^{\prime \prime}$

By inserting Eq. (B.12) into Eq. (B.10) we get

$w^{(5)}-\frac{k}{E A_{1, \mathrm{sh}}} \frac{E I_{\infty}}{E I_{0}} w^{\prime \prime \prime}=\frac{1}{E I_{0}} \frac{k}{E A_{1, \mathrm{sh}}} H_{\mathrm{w}}$

Also, we rewrite Eq. (B.9) in the following form

$u_{1}^{\prime \prime \prime}-\frac{k}{E A_{1, \mathrm{sh}}}\left(\frac{E A_{0, \text { red }}}{E A_{2}}\right) u_{1}^{\prime}=\frac{1}{h_{0}} \frac{E I_{0}}{E A_{2}} w^{(4)}-h_{0} \frac{k}{E A_{1, \mathrm{sh}}}\left(\frac{E A_{0, \mathrm{red}}}{E A_{2}}\right) w^{\prime \prime}$

Apparently, Eqs. (B.13) and (B.14) are exactly equivalent to the original set of eighth-order differential Eq. (B.5). It should be pointed out that Eq. (B.13) is corresponding to a sixth-order differential equation presented in Girhammar et al. [19] for dynamic analysis of a partially interacting beam composed of three symmetric coinciding layers in contrast to the present stabilising element in which there are sheathing webs between the framing layers. The rotation function can also be determined using the last of Eq. (B.5) in terms of $w$ only:

$\varphi=-w^{\prime}+\frac{1}{K_{\mathrm{s}}} \frac{H_{\mathrm{w}}}{G A_{0}}$

\section{Appendix C. Details on solution of the governing equations}

Solution procedure of the new set of governing Eqs. (17) are described here. First, the uncoupled fifth-order equation in Eq. (17.1) should be solved, independently. Second, the obtained solution should be substituted into the right-hand side of the third-order differential equation in Eq. (17.1) and the resulting uncoupled inhomogeneous third-order equation can be solved independently for determining the displacement, $u_{1}$. Third, the unknown functions $u_{2}$ and $u_{3}$ can be determined by substituting the obtained solutions of $\varphi$ and $u_{1}$ into Eq. (17.2).

The complete solution of the first of Eq. (17.1), can be represented as

$w=w_{\mathrm{G}}+w_{\mathrm{P}}$

$w_{\mathrm{G}}(x)=c_{3}+c_{4} x+c_{5} x^{2}+c_{6} \cosh (\lambda x)+c_{7} \sinh (\lambda x)$

$w_{\mathrm{P}}(x)=-\alpha H_{\mathrm{w}} x^{3}$

where

$\lambda=\sqrt{\frac{k}{E A_{1, \mathrm{sh}}} \frac{E I_{\infty}}{E I_{0}}}, \quad \alpha=\frac{1}{6 E I_{\infty}}$

where the subscripts ' $\mathrm{G}$ ' and 'P' indicate the general and particular part of the solutions, respectively. Substituting Eq. (C.1) into the second of Eq. (17.1) yields the following nonhomogeneous differential equation

$u_{1}^{\prime \prime \prime}-\mu^{2} u_{1}^{\prime}=-2 c_{5} h_{0} \mu^{2}+\lambda^{2}\left(\beta \lambda^{2}-h_{0} \mu^{2}\right)\left[c_{6} \cosh (\lambda x)+c_{7} \sinh (\lambda x)\right]+6 h_{0} \mu^{2} \alpha H_{\mathrm{w}} x$

where

$\mu=\sqrt{\frac{k}{E A_{1, \mathrm{sh}}} \frac{E A_{0, \mathrm{red}}}{E A_{2}}}, \quad \beta=\frac{1}{h_{0}} \frac{E I_{0}}{E A_{2}}$

The complete solution of Eq. (C. 3 ) is expressed in the form

$u_{1}=u_{1 \mathrm{G}}+u_{1 \mathrm{P}}$

$u_{1 \mathrm{G}}(x)=c_{8}+c_{9} \cosh (\mu x)+c_{10} \sinh (\mu x)$

$u_{1 \mathrm{P}}(x)=2 c_{5} h_{0} x+\frac{\lambda\left(\beta \lambda^{2}-h_{0} \mu^{2}\right)}{\lambda^{2}-\mu^{2}}\left[c_{6} \sinh (\lambda x)+c_{7} \cosh (\lambda x)\right]-3 h_{0} \alpha H_{\mathrm{w}} x^{2}$

The rotation function, $\varphi$, is determined from substitution of Eq. (C.1) into the first of Eq. (17.2) as

$\varphi(x)=-c_{4}-2 c_{5} x-\lambda\left[c_{6} \sinh (\lambda x)+c_{7} \cosh (\lambda x)\right]+3 \alpha H_{\mathrm{w}} x^{2}+\frac{1}{K_{\mathrm{s}}} \frac{H_{\mathrm{w}}}{G A_{0}}$

Now, we substitute the solutions (C.5) and (C.6) into the second and third of Eq. (17.2), and use the definition of the coefficients $\lambda$ and $\mu$ from 
(C.2) and (C.4), and obtain

$$
\begin{aligned}
u_{2} & =-h_{0} c_{4}+\zeta_{1}\left[c_{6} \sinh (\lambda x)+c_{7} \cosh (\lambda x)\right]+c_{8} \\
& +\zeta_{2}\left[c_{9} \cosh (\mu x)+c_{10} \sinh (\mu x)\right]+h_{0}\left(6 \frac{E A_{1, \mathrm{sh}}}{k} \alpha+\frac{1}{K_{\mathrm{s}} G A_{0}}\right) H_{\mathrm{w}} \\
u_{3} & =-2 c_{4} h_{0}-2 c_{5} h_{0} x+\zeta_{3}\left[c_{6} \sinh (\lambda x)+c_{7} \cosh (\lambda x)\right]+c_{8} \\
& +\zeta_{4}\left[c_{9} \cosh (\mu x)+c_{10} \sinh (\mu x)\right]+\left(12 \frac{E A_{1, \mathrm{sh}}}{k} \alpha+\frac{2}{K_{\mathrm{S}} G A_{0}}+3 \alpha x^{2}\right) h_{0} H_{\mathrm{w}}
\end{aligned}
$$

where

$\zeta_{1}=0, \zeta_{2}=-\frac{2 E A_{1, \mathrm{sh}}}{E A_{2}}, \zeta_{3}=\frac{E I_{0}}{2 h_{0} E A_{1, \mathrm{sh}}} \lambda, \zeta_{4}=1$

The constant coefficients $c_{i}(i=3,4,5, \ldots, 10)$ are to be determined from the eight remaining boundary conditions which are expresses as

at $x=0: u_{1}=u_{2}=u_{3}=\varphi=w=0$

at $x=L: u_{1}^{\prime}=u_{2}^{\prime}=\varphi^{\prime}=0$

Satisfying the boundary conditions (C.9) will result in a set of eight algebraic equations. The solution of this set of equations, after simplification, can be represented as

$$
\begin{aligned}
& c_{3}=-c_{6}=-\frac{2\left(h_{0} E A_{1, \mathrm{sh}}\right)^{2}}{k E I_{\infty}^{2}} \frac{\tanh (\lambda L)}{\lambda} H_{\mathrm{w}} \\
& c_{4}=\left[\frac{2\left(h_{0} E A_{1, \mathrm{sh}}\right)^{2}}{k E I_{\infty}^{2}}+\frac{1}{K_{\mathrm{s}}} \frac{1}{G A_{0}}\right] H_{\mathrm{w}} \\
& c_{5}=\frac{L}{2 E I_{\infty}} H_{\mathrm{w}} \\
& c_{7}=-\frac{2\left(h_{0} E A_{1, \mathrm{sh}}\right)^{2}}{k \lambda E I_{\infty}^{2}} H_{\mathrm{w}} \\
& c_{8}=-\frac{h_{0} E A_{1, \mathrm{sh}} E I_{0}}{k E I_{\infty}^{2}} H_{\mathrm{w}} \\
& c_{9}=c_{10}=0
\end{aligned}
$$

It can be shown that the axial displacement of the intermediate framing member, in absence of the external normal force, is zero due to the symmetry in both geometry and constituent materials of the stabilising wall element with respect to its middle plane. Also, as expected, it can be shown by inserting Eq. (C.10) into Eqs. (C.5) and (C.7) that the absolute values of the axial displacements of the upper and lower framing members are identical. i.e.,

$u_{1}=-u_{3}$

$u_{2}=0$

\section{References}

[1] Girhammar UA, Atashipour SR. Analysis of shear deflections of deep composite boxtype of beams using different shear deformation models. Comput Struct 2015;155:42-53.

[2] Tlustochowicz G. Stabilising system for multi-storey beam and post timber buildings (Doctoral Thesis). Luleå: Luleå University of Technology; 2011.

[3] Atashipour SR. Structural analysis of deep composite box-type components with application to a proprietary stabilising timber wall element (Doctoral Thesis). Luleå: Luleå University of Technology; 2016.

[4] Arnovljevic I. Das Verteilungsgesetz der Haftspannungen in axial bean- spruchten Verbundstäben. Zeitschrift für Architektur und Ingenieurwesen 1909:415-7.

[5] Fillunger P. Über die Festigkeit der Löt-, Leim- und Nietverbindungen. Österreichische Wochenschrift für den öffentlichen Baudienst 1919;25:78-87.

[6] Volkersen O. Die nietkraftverteilung in zugbeanspruchten nitverbindungen mit konstanten laschenquerschnitten. Luftfahrtforschung 1938;15:41-7.

[7] Goland M, Reissner E. The stresses in cemented joints. ASME J Appl Mech 1944;11:A17-27.

[8] Allman DJ. A theory for elastic stresses in adhesive bonded lap joints. Q J Mech Appl Mech 1977;30:415-36.

[9] Chen D, Cheng S. An analysis of adhesive-bonded single-lap joints. ASME J Appl Mech 1983;50:109-15.
[10] Norris CB, Ericksen WS, Kommers WJ. Flexural rigidity of a rectangular strip of sandwich construction-comparison between mathematical analysis and results of tests Technical Report, Report 1505A W.I. Madison: Forest Products Laboratory; 1952.

[11] Plantema FJ. Sandwich construction. New York: Wiley; 1966.

[12] Allen HG. Analysis and design of structural sandwich panels. Oxford: Pergamon Press; 1969.

[13] Girhammar UA, Gopu KA. Composite beam-column with interlayer slip- exact analysis. J Struct Eng 1993;119:1265-82.

[14] Girhammar UA, Pan DH. Exact static analysis of partially composite beams and beam-columns. Int J Mech Sci 2007;49:239-55.

[15] Challamel N, Girhammar UA. Variationally-based theories for buckling of partial composite beam-columns including shear and axial effects. Eng Struct 2011;33:2297-319.

[16] Xu R, Wu Y. Static, dynamic, and buckling analysis of partial interaction composite members using Timoshenko's beam theory. Int J Mech Sci 2007;49:1139-55.

[17] Bresse JAC. Cours de mécanique appliquée-Résistance des matériaux et stabilité des constructions. Paris: Gauthier-Villars; 1859. [in French].

[18] Timoshenko SP. Strength of materials. 1st ed. New York: van Nostrand Co.; 1930.

[19] Girhammar UA, Pan DH, Gustafsson A. Exact dynamic analysis of composite beams with partial interaction. Int J Mech Sci 2009;51:565-82. 